\title{
Análisis del diseño de los contratos en el proceso de subcontratación de las organizaciones públicas, el caso de Emcali EICE
}

Henry Caicedo ${ }^{1}$ versidad del Valle. Profesor de la Facultad de Ciencias de la Administración en la Universidad del Valle. Director del Observatorio de Prospectiva Tecnológica e Industrial para la Competitividad Regional (OPTICOR). 


\section{Introducción}

El presente documento usa el marco de las categorías analíticas de la economía institucional para evaluar el impacto que sobre la eficiencia de la organización de las Empresas Municipales de Cali Emcali EICE ha tenido la tercerización o outsoursing de muchos de los procesos productivos necesarios para la generación de los servicios públicos. A partir de un tratamiento exhaustivo de los contratos que Emcali firma con los proveedores, se evalúan dos aspectos centrales de la eficiencia de las empresas estatales: el desvío de recursos públicos a manos privadas y el problema de la definición del tamaño óptimo de la empresa.

En este documento se parte del hecho que en Colombia desde principios de los 90 se inició un proceso de modernización del Estado incluyendo al conjunto de sus organizaciones, con este propósito en 1993 se emitieron la ley 142, 143 que establecen los términos de la generación de esta clase de servicios y la ley 80 que regula la contratación publica. Estas leyes en su conjunto tratan de que la generación de los servicios públicos estén regulados por los principios y supuestos de la competencia de los mercados, y fundamentan la aplicación del modelo de la nueva administración publica el cual a su vez encuentra su fundamentación en la economía neoclásica, este modelo para el diseño de las organizaciones sugiere las siguientes prescripciones:
Un condicionante importante del modelo es que los acuerdos contractuales, ya sean explícitos o implícitos, se elaboren en un marco jurídico estable y legítimo; se requiere que el número de participantes en cada transacción o acuerdo sea lo suficientemente grande como para que se cumplan las condiciones competitivas; es preciso que la información necesaria para tomar decisiones esté disponible y simétricamente distribuida entre los participantes de los contratos que se ejecuten en la organización; además se exige que los derechos de propiedad sobre los activos que se transan dentro y en las fronteras de la empresa estén bien definidos, de tal manera que se pueda efectuar un reparto de los rendimientos acorde al aporte que cada individuo haga a la organización; por último que los contratos o acuerdos sean completos en el sentido que la ley pueda dirimir las disputas a bajo costo.

Emcali, en la aplicación del nuevo modelo de administración pública, ha experimentando un proceso de externalización de los insumos y procesos necesarios para la generación de los servicios públicos; hoy la empresa encarga a proveedores la realización de actividades de servicios de asesoría contable y jurídica, también demanda la reparación, fabricación y mantenimiento de plantas de acueducto, energía y telefonía; se sabe que los servicios de atención al público, funciones secretariales, provisión de alimentos a los trabajadores, limpieza de 
canales de aguas lluvias, son provistos a las empresas municipales de Cali, por terceros; la tendencia es profundizar en este proceso de subcontratación con el fin de reducir el costo de la empresa y modernizar la organización.

Pese a los cambios y nuevas leyes la empresa enfrenta la crisis más profunda de su historia, ésta se manifiesta en varios elementos problemáticos:

a) Deficiente manejo administrativo. b) Niveles de endeudamiento no sostenibles. c) Suscripción de contratos onerosos. Si bien es cierto que los servicios no se han dejado de prestar, su cobertura y calidad no ha variado significativamente desde los 90 (Varela, 2002, Pág. 20)

Para analizar el por qué pese a los esfuerzos de modernización, Emcali enfrenta la crisis mas grande de su historia, debe tenerse en cuenta que el nuevo modelo de gestión pública le impuso a las empresas públicas como Emcali entrar en un profundo proceso de subcontratación, el cual requiere de la formulación y diseño de un gran número de contratos con proveedores. En el diseño de estos se establecen: qué puede y qué no puede hacerse en una transacción, a la vez cómo se percibirán los beneficios que involucre el reparto de los recursos; es allí donde los agentes participantes de la organización encuentran la oportunidad para actuar a favor o en contra de la empresa. Por consiguiente para aproximarse al estudio de la problemática que hoy enfrenta Emcali, es preciso analizar el diseño de los contratos que Emcali firma con los proveedores para determinar si el proceso de subcontratación ha incidido positiva o negativamente en la eficiencia de la empresa en los últimos cinco años.

Para efectuar el análisis de eficiencia en un proceso de subcontratación, se requiere resolver algunos interrogantes:

$¿$ Cuáles son los principales factores que determinan el diseño económico de los contratos que se establecen entre la organización EmcaliI y los proveedores?

¿Cuál es la probabilidad de que un contrato establecido entre Emcali y los proveedores experimente fallas en el diseño económico?

¿Qué consecuencias genera el que un contrato esté mal diseñado en la estructura de costos de Emcali?

En el presente trabajo se intenta mostrar que pese a existir leyes y resoluciones jurídicas que reglamentan la contratación de las organizaciones públicas como Emcali y los proveedores, los contratos entre estas partes experimenta fallas en el diseño económico, esto implica que los participantes de las transacciones encuentran espacio para el oportunismo y extraer recursos públicos para su propio beneficio.

Mediante la aplicación de la técnica de la regresión logística, se mostrará que la probabilidad de que un contrato establecido entre Emcali y los proveedores esté mal diseñado es positiva y está en relación inversa al valor del contrato y directa al riesgo de ejecución, además se muestra que 
muchos elementos constitutivos del diseño de los contratos, como el tiempo de duración, valor de las pólizas, multas, garantía, entre otros, no contribuyen a corregir el diseño de los contratos y por consiguiente, a evitar la posible perdida de eficiencia de las organizaciones como Emcali en el logro de los objetivos.

Este trabajo avanza hasta mostrar que el mal diseño económico de los contratos, afecta negativamente a la eficiencia de las organizaciones públicas como Emcali, en la medida generan en la empresa costos de transacción que se evidencian en la ejecución de procesos de subcontratación de bienes y servicios adquiridos mediante suscripción de contratos onerosos que menoscaban la estructura de costos de Emcali e impide que ésta alcance mejores niveles de eficiencia económica.

Este documento intenta satisfacer los siguientes objetivos: identificar los elementos problemáticos del proceso de subcontratación en las organizaciones públicas como Emcali; diseñar una metodología para identificar cuando un contrato está bien o mal diseñado en el aspecto económico; evaluar el impacto que sobre la eficiencia de las organizaciones de esta clase ejerce la contratación en el marco legal en Colombia.

Este trabajo se divide en 5 partes, la primera es esta introducción, en la segunda se plantea el marco teórico; en la tercera se hace una presentación del marco estadístico en el que se hace referencia sobre la población, tamaño de la muestra, y las variables a calcular. En la cuarta se realiza el análisis de la información extraída de los contratos; y por último, se plantean un conjunto de conclusiones.

\section{Análisis de la eficiencia de la organización y su relación con el outsourcing}

En este apartado se propone encontrar la relación entre los dos conceptos fundamentales del nuevo modelo de gestión pública: la eficiencia de las organizaciones y el proceso de outsourcing o subcontratación; a manera de reflexión anticipada se espera mostrar que ambos conceptos no son necesariamente complementarios, el grado de complementariedad va a depender de la forma como se diseñen los contratos, porque según el diseño se estará más cerca o lejos de la eficiencia de una organización pública o privada.

\subsection{El concepto de externalización o outsourcing en las organizaciones públicas}

Para los fines de esta investigación se entiende como externalización de servicios públicos a la transferencia de actividades que una organización publica ha estado realizando y que por razones estratégica $\mathrm{y} / \mathrm{o}$ de costo se encomienda a otra organización o persona natural. La transferencia de la actividad o de la prestación del servicio al contratista externo no exime a la Administración Pública de la respon- 
sabilidad ante los usuarios del servicio. Desde el punto de vista de la administración pública, se habla de dos tipos o clases de externalización: Una primera llamada externalización táctica, coyuntural o competitiva, destinada a resolver la escasez temporal de recursos o las variaciones de capacidad que enfrenta la empresa; una segunda llamada externalización estratégica, de especialidad o cooperativa cuyo objetivo es aprovechar una determinada especialización del proveedor. Conviene destacar que la externalización no es un concepto jurídico, sino de gestión; pero que al estar respaldada por un contrato, los procesos de externalización están regulados por las leyes jurídicas vigentes. (Sabaté Jordi M. Pág. 3. 2001)

La subcontratación como técnica de la administración pública moderna, presupone que si una actividad puede brindarla el sector privado con eficiencia no debe ser ejecutada por el sector público; en esa perspectiva, la externalización de los servicios públicos va desde la delegación completa de una empresa pública en otra privada hasta la provisión de servicios personales. Constituyen casos de externalización de delegación completa cuando la organización pública encomienda a otra privada la generación de un servicio publico como la provisión de energía o telefonía celular y fija, en este caso se le asigna el derecho de propiedad a la entidad particular para que usufructúe las ganancias derivadas del servicio; constituyen casos de externalización parcial, cuando una empresa pú- blica otorga una franquicia a un particular para que durante cierto tiempo provea a la sociedad de un tipo particular de servicio público, por ejemplo, cuando Emcali otorgó a megaproyectos la franquicia de proveer alumbrado público a la ciudad de Cali durante 15 años.

No obstante, los casos de externalización parcial o completa, el proceso de subcontratación más recurrente es aquel mediante el cual una empresa pública, adelgaza su tamaño y acude a proveedores para suministrarse los insumos que no puede producir. Las actuales reformas administrativas en las organizaciones públicas, subcontratan desde los servicios de aseo y cafetería, hasta los servicios de potabilización del agua, provisión de cableado para energía y telefonía, apoyo y asesoría jurídica, etc.

En el proceso de externalización, La organización que recibe la responsabilidad de prestar el servicio o proveer a las organizaciones públicas, ha de ser diferente y estar separada de aquella que se responsabiliza de la provisión del servicio (esto es, de aquella que identifica la necesidad de la prestación y planifica cómo se va a satisfacer). La organización puede ser pública o privada, con o sin ánimo de lucro. Dicha organización puede ser completamente ajena a la Administración Pública o puede tener su origen en la transformación de una unidad perteneciente a la Administración. El proceso competitivo implica la existencia de un concurso público en el que haya Competidores o diferentes operadores 
dispuestos a concurrir en la prestación del servicio (Sabaté Jordi M. Pág. 3. 2001)

Conceptualmente, la externalización se apoya en el principio de privatización y contractualización, según el cual las actividades que puedan ser desarrolladas por el sector privado no tienen que ser retenidas por el sector público. Cuando se trata de sustituir la realización de actividades con personal y recursos propios por la prestación contratada con un proveedor externo, la normativa de contratación prevé diferentes modalidades, Algunas de ellas son:

Los conciertos, en los cuales se aprovechan las instalaciones y los recursos mediante los cuales el adjudicatario ya presta el servicio que ahora se contrata públicamente (por ejemplo: la generación de alumbrado público por parte de una entidad privada que aprovecha la infraestructura ya disponible); las concesiones, en las cuales se regulan los precios de mercado, unas tarifas de servicios y a menudo, la inversión en infraestructura que ha de realizar la empresa concesionaria (por ejemplo: el servicio de inspección técnica de vehículos o ITV)

Cuando se transforman las unidades propias que prestan un servicio en unidades externas que compiten en un mercado abierto para seguir prestando el servicio se recurre a otras modalidades. Por ejemplo, a la creación de sociedades anónimas, de capital mixto público y de los trabajadores, o a la creación de cooperativas formadas por profesionales internos que extinguen su víncu- lo con la Administración Pública y se hacen cargo de un servicio público en competencia con el sector privado y otros grupos profesionales (Sabaté Jordi M. Pág. 4. 2001).

El uso de la externalización en la Administración Pública se justifica en la necesidad de alcanzar mayores niveles de eficiencia, más flexibilidad, menor componente de costos fijos o una combinación de las anteriores. También permite, mediante la fórmula del contrato, saber con mayor precisión qué se está haciendo en las unidades administrativas y con qué coste. Asimismo se consideran las ventajas estratégicas de contar con proveedores altamente especializados.

Además La subcontratación permite la reducción del tamaño de la empresa a través del despido del personal, elimina divisiones internas y hasta departamentos completos con sus funciones y tareas, en ese sentido la subcontratación genera disminución de costos laborales y organizativos; este es el principal argumento sobre el cual se han fundado las nuevas teorías de la administración pública.

El outsourcing se sustenta en las ventajas que proporciona el mercado en la provisión de bienes y servicios, la subcontratación invita a conformar múltiples empresas privadas capaces de proveer de insumos a las empresas públicas, mediante un proceso de selección, basado en el precio y la calidad; la empresa pública elige la más eficiente de las organizaciones; la idea es que durante un proceso repetido de selección las empresas competidoras tende- 
rán a volverse mas eficientes para ganar las licitaciones. La combinación de reducción de costos y aumento de calidad han hecho del outsourcing, la técnica organizativa mas recurrente en la administración moderna. La externalización introduce unos factores novedosos en la cultura pública, entre otros:

Las Fuerzas de mercado, uno de los principales instrumentos de las políticas de modernización, que inducirán desde la aplicación de técnicas de mejora, hasta el replanteamiento del papel del Estado en la cobertura de necesidades sociales; la competencia, se espera que la presión competitiva abarate costos, aumente la calidad y la cobertura en la provisión de toda clase de servicios públicos; en la medida que el desarrollo de la competencia, abra y elimine los monopolios públicos, introduzca mejoras de economía, eficiencia y calidad en la prestación de los servicios.

La separación de las funciones de provisión de servicios de las de prestación de servicios es una separación clave en el nuevo modelo organizativo en la medida que elimina de la empresa pública, costos de producción y control, y supuestamente, esta puede redireccionar los esfuerzos a la planificación y mejora en la prestación de los servicios.

El carácter novedoso de la externalización en la Administración Pública conlleva riesgos, el primero de ellos subyace en la no diferenciación entre la filosofía de la externalización competitiva y la externalización cooperativa. La presión creciente sobre los recursos públicos lleva a externalizar aplicando generalmente los principios de la externalización competitiva, independientemente del tipo de servicios que se externalicen. Esto sólo puede concluir en un fracaso de la prestación del servicio. Un ejemplo de este error en la era de las privatizaciones lo constituye la privatización del agua en zonas rurales con criterios mayoritariamente competitivos: no hace falta detallar qué consecuencias tendría para los habitantes rurales depender de un prestador de servicios de acueducto que persigue la maximización de beneficios y la reducción de costes.

El segundo riesgo, se deriva de la intensidad en el uso de la subcontratación competitiva, esta forma de externalizar trae como consecuencia un entorno inestable, basado en relaciones contractuales a corto plazo, extremadamente competitivas y que no pueden sino repercutir negativamente en los empleados y en los ciudadanos en general; la externalización competitiva la más recurrente en la nueva gestión pública se caracteriza por: abusar de la contratación temporal y por recurrir a trabajadores de tiempo parcial.

Desgraciadamente, los factores que impulsan a la externalización de servicios públicos son a menudo de índole económica, de búsqueda de una reducción de costes a corto plazo, como respuesta a un entorno inestable. Esto induce procesos de externalización de tipo competitivo que, a su vez, generan más inestabilidad del entorno, marcadamente negativo, en el que los beneficiarios son una minoría. 
2.2. El diseño de los contratos y su impacto en la eficiencia económica en los procesos de subcontratación de las organizaciones

Para encontrar la relación entre eficiencia de las organizaciones y el diseño de los contratos en el proceso de subcontratación, es necesario plantear la definición de eficiencia en las organizaciones sobre la cual se construye este trabajo: se afirma que una organización es eficiente cuando tomando los resultados de beneficios, objetivos y metas en dos periodos de tiempo, los resultados del período anterior son menores a los del período siguiente (Milgron y Roberts, 1993, pág 28). En esa perspectiva es indispensable para los fines de este artículo una noción de empresa, en la teoría de la economía institucional se concibe a la organización como una red de contratos que cumplen la función de definir las reglas del juego mediante las cuales la organización se relaciona con los miembros internos y externos. En esa perspectiva el problema central de las organizaciones modernas con el nuevo modelo de administración pública en relación con el diseño de los contratos, es definir: qué actividades deben realizarse al interior de la organización y cuáles debe adquirir en el mercado. Esto impone como tarea efectuar una revisión de la naturaleza de las transacciones, el tipo de inversión y diseños de los contratos a que se ve abocada una empresa pública en los procesos de subcontratación; a partir del tratamiento de estas cuestiones se podrán construir un conjunto de crite- rios que faciliten el tratamiento de los procesos de subcontratación y su relación con la eficiencia de las organizaciones públicas (Williamson, 1989, Pág. 106).

Siguiendo los principios de la economía de las organizaciones, La eficiencia de éstas va a depender en grado sumo del diseño de las transacciones económicas a que se ve enfrentada la empresa u organización en el proceso de externalización de las actividades y procesos productivos en la generación de servicios públicos. $\mathrm{La}$ ejecución eficiente de una transacción económica, debe regirse por tres principios: el jurídico o legal, el económico y el principio jerárquico u organizacional. El principio jurídico o legal le viene dado a los participantes del contrato, entonces estos acomodan sus comportamientos según la institucionalidad de la ley; además, los principios de derecho legal suelen ser lo suficientemente amplios como para dar cabida a la mayor cantidad de contratos independientemente del tipo de negociación y objeto de la transacción.

La teoría del derecho ha identificado tres clases de contratos de compraventa de bienes y servicios que pueden aplicarse a los contratos administrativos: los contratos clásicos, entran en esta categoría aquellos que se redactan de manera explicita y en los que se confía plenamente en la capacidad de los tribunales para dirimir los conflictos al menor y mas bajo costo posible. Los contratos neoclásicos, constituyen este grupo de contratos aquellos en los que se reconoce com- 
plejidad en la negociación por consiguiente se introducen dispositivos para salvaguardar la transacción, caben en estos contratos la inclusión de expertos o peritos en la materia objeto del negocio. La última clase de contratos son los denominados relacionales, estos se firman para el largo plazo 5, 10 o 30 años, en estos se reconoce que ni la ley ni los expertos en la materia son capaces de dirimir las disputas entre los participantes, entonces se fijan salvaguardas lo suficientemente amplias como para que los participantes puedan ajustarse según las circunstancias del negocio. Cada una de esta clase de contratos debe aplicarse a un tipo particular de transacciones, es decir, algunas transacciones deben circunscribirse jurídicamente a los contratos clásicos, otras a los neoclásicos y un conjunto particular a los contratos relacionales; una aplicación de un contrato a una transacción de bienes y servicios equivocada, probablemente generará ineficiencia económica en las organizaciones. (Williamson O, 1989, pág 77-80).

La eficiencia de las organizaciones además del diseño de los contratos y la asignación de recursos, debe tener en cuenta los principios de la organización. En el presente trabajo se presta especial atención a los principios organizativos desarrollados por Hebert Alexander Simon; según este autor la organización se caracteriza por un conjunto de principios, a saber:
Una organización eficiente ha de diseñar una jerarquía y principios de autoridad que faciliten el control de los miembros e integrantes de ésta; a su vez la organización debe poseer mecanismos de información, de tal manera que no existan ni desperdicios ni costos de recursos derivados de mala y asimétrica distribución de la información entre unidades y miembros de la empresa. Por otra parte, el principio de lealtad e incentivos, aunque se suelen tratar por separado, se pueden manejar dentro de la categoría de incentivos; el manejo de estos dentro de una organización cumple el especial papel de alinear los intereses de los miembros de ésta, es aquí donde el director de las organizaciones ha de prestar mayor atención en el logro de los objetivos y la eficiencia, entre mas comprensivo y claro sea el diseño de los incentivos, más cerca se estará del logro de los objetivos trazados por la organización ${ }^{2}$.

El principio económico de las organizaciones evalúa tres aspectos de las transacciones: el tipo de inversión, la especificidad de los activos y la frecuencia: Especificidad de los activos: esta es una categoría analítica que Williamson ha aportado al lenguaje de la economía de las organizaciones, se entiende como especificidad de los activos a el grado de compromiso que adquiere un activo en una transacción: un activo es de baja especificidad cuando debido a las características del

\footnotetext{
2 Ver Alexander Simon: "El Comportamiento Administrativo".
} 
bien o servicio a ofrecer el proveedor no queda atado a un cliente particular; contrariamente un activo se considera de alta especificidad cuando el proveedor y/o el cliente quedan atrapados en una relación de largo plazo por efecto de una negociación de un bien o servicio. Según Williamson los activos pueden transformarse en altamente específicos en cuatro situaciones, lo cual permite clasificarlos en cuatro clases: activos muy específicos debido al capital humano, activos altamente específicos debido a la localización de los recursos, activos específicos debido a la dedicación de los recursos, y activos altamente específicos debido a las clases de inversión, y por último, los activos altamente específicos debido al capital físico, fundamentalmente herramienta de alta tecnología (Williamson, 1989, pág 103).

Una vez evaluada la especificidad de los activos se analiza los tipos de inversión. Una inversión se clasifica como estandarizada cuando los recursos empleados por el proveedor se ejecutan en la producción de bienes o servicios de baja especificidad de los activos y escasa complejidad tecnológica por lo que pueden ser utilizados en una multiplicidad de usos alternativos, por consiguiente no existirá dependencia del proveedor con ningún cliente.

Las inversiones que realizan los proveedores pueden también clasificarse como mixtas cuando el bien o servicio ofrecido por el proveedor configura una especificidad de activos intermedia y exige algún grado de complejidad tecnológica, el carácter mixto proviene del hecho que el proveedor tiene algún grado de diversificación de la inversión pudiendo encontrarle al producto ofrecido algunos usos alternativos en menor grado que las inversiones estandarizadas. La tercera clasificación de la inversión que realiza un proveedor, se denomina inversiones idiosincrásicas, opera cuando el proveedor genera un bien o servicio de alta especificidad de los activos y a su vez de complejidad tecnológica, lo cual lleva a que el proveedor quede atrapado en una relación de largo plazo con el cliente y no pueda darle a la inversión ningún uso alternativo (Williamson, 1989, Pág. 80-89).

\section{Clasificación de las transacciones según la frecuencia}

Se consideran de transacciones de alta frecuencia a aquellas en las que el proveedor y cliente transan continuamente unidades de un bien o servicio durante un tiempo lo suficientemente largo como para que la inversión pueda redituarse a bajo costo del capital por unidad de transacción; así mismo, se consideran transacciones de frecuencia ocasional a aquellas que se ejecutan en intervalos cortos de tiempo, por lo que el proveedor y el cliente transan ocasionalmente; por consiguiente, las partes intentan recuperar el total del retorno de la inversión en el momento de la transacción.

La teoría de la economía institucional en su acápite de las organizaciones presupone que todo contrato en un proceso de subcontratación e in- 
tercambio son intrínsecamente incompletos, lo cual ocasiona costos de transacción. En la ortodoxia económica un contrato se considera como completo, cuando las partes prevén todas las contingencias y las escriben en el contrato, además debe cumplirse que la información entre los agentes sea simétrica y cuando no sea posible los tribunales deben tener la facultad para garantizar que la información sea verificable por terceros al menor costo factible. La teoría de los costos de transacción afirma que cuando alguna de las anteriores condiciones no se cumple, el contrato será incompleto; el primer problema subyace en el reconocimiento de la asimetría de la información. En segundo término, el origen de la incompletitud de los contratos se halla en la presencia de activos altamente específicos, en las transacciones, esto implica que las partes en algunos procesos de subcontratación tienen que hacer inversiones especificas; Una vez firmado el contrato y hecha la inversión especifica, alguno de ellos puede obtener poder monopólico sobre el otro; este poder surge a pesar de que ex ante haya una competencia perfecta (licitación para el caso de la contratación estatal).

La tercera fuente de la incompletitud es el costo de negociación. La solución para el peligro del oportunismo es el diseño de un contrato completo. Pero su negociación es costosa debido al numero infinito de contingencias que los agentes tienen que prever. Cuanto más complejo es el ambiente, más costoso es redactar un contrato completo (Sausiier 2000). Los agentes tienen el incentivo de reducir el grado de la completitud del contrato y de ahorrar los costos de transacción ex ante. Pero al ahorrar costos ex ante, el agente - dueño de la obra se expone al peligro de una conducta oportunista por parte de la contratista. El oportunismo de contratista aumenta el costo de transacción ex post. Lo que obliga al dueño a balancear entre los dos costos (Crocker y Reynolds 1993).

En cuarto término, es la inverificabilidad de muchas contingencias por la tercera parte que casi siempre la ejercen los tribunales, quienes en muchas ocasiones no disponen los recursos técnicos y financieros para prever el total de las contingencias que pueden ocurrir en una transacción; Esto ocurre en los casos de la inversión específica, confianza etc. Como resultado los contratos reales se hacen incompletos en distinto grado (Gorvanev Yury 2002 pag-4).

Un contrato real se puede ubicar en un punto del continuum que va desde la completitud total a la incompletitud total, de acuerdo con la teoría de los costos de transacción, el grado de la completitud de contratos, elegida por las partes, refleja su deseo de minimizar el costo de la transacción. En un contrato incompleto los agentes no son capaces de comprometerse a cierta división de la ganancia adicional resultante, antes de hacer sus decisiones no observables sobre la inversión. Como resultado las utilidades postcontractuales tienen que ser redistribuidas más tarde, en el proceso 
de la renegociación. Pero la perspectiva de la renegociación distorsiona los incentivos de los agentes a invertir y disminuye las ganancias comunes de los dos agentes. Las partes tratan de superar el oportunismo ex post y el desincentivo a invertir a través de un contrato más completo. Pero esto tiene un costo; el de preparar un contrato contingente ex ante (Yuri Gorbaneff, Pág. 4, 5.)

La teoría de las organizaciones creadas por Coase y Williamson, se han fundamentado en desarrollar un cuerpo teórico capaz de relacionar lo económico, lo jurídico y lo organizativo de un contrato para reducir el oportunismo de los agentes; estos autores presuponen que para cada transacción económica existe: un tipo de contrato jurídico, una forma particular de coordinación en la asignación de los recursos, y un nivel satisfactorio de los principios organizacionales; a la combinación de todos estos elementos Williamson la denomina como estructura de gobernación eficiente de las transacciones, la cual es la única forma de llevar a cabo una negociación de tal manera que se minimizan los riesgos de oportunismo y se maximicen los beneficios derivados de la negociación.

Para que un tipo de coordinación como una forma de asignar los recursos sea eficiente, requiere que las inversiones se efectúen según la especificidad de los activos y la frecuencia de la transacción: así, para que cuando una inversión que se clasifique como estandarizada sea rentable, es necesario que se efectúe en bienes y servicios que involucren transacciones de alta frecuencia, y para que sea eficiente dicha transacción debe acudirse a los principios del mercado, es decir, con un gran número de competidores para que el precio coordine las acciones del conjunto de participantes.

En el caso que la inversión tenga algún grado de especialización, y se constate que la frecuencia es ocasional, para obtener el máximo de la eficiencia en la inversión, debe apelarse a las transacciones coordinadas por árbitros, o lo que en la literatura de la economía de las organizaciones se conoce como gobernación trilateral. Por último, si las inversiones necesarias son idiosincrásicas o muy especializadas, y se sabe de antemano que el bien a proveer es de alta frecuencia, para garantizar el máximo de los beneficios derivados de la inversión, es necesario apelar a la coordinación unificada o bilateral, como los tipos de coordinación apropiados para evitar y minimizar los desperdicios derivados de usar el mercado en tales situaciones. En el caso que se designe como una transacción de gobernación bilateral, operará el proceso de subcontratación bajo la modalidad de un contrato de largo plazo. No obstante si la transacción se ubica bajo la estructura de gobernación unificada, no habrá subcontratación, pues la empresa u organización realizará dicha actividad bajo su propiedad y control.

Simon, Coase y Williamson, presuponen que una firma u organización si quiere ser eficiente, ha de reconocer que las actividades de la organización 
son diferentes en el sentido de la frecuencia de las transacciones, el tipo de inversión, el tipo de contrato y la clase de coordinación. La teoría de las organizaciones creada por estos tres autores, proponen un conjunto de criterios que deben seguir cada actividad dentro de la empresa para ejecutarla y llevarla a cabo de manera eficiente. En el cuadro número 1 se describe el conjunto de criterios que debe aplicarse a cada actividad dentro de la empresa según el tipo de transacción.

En el siguiente cuadro se presentan los diferentes tipos de coordinación que se dan a lugar dependiendo del contexto de la transacción. En las filas se encontrarán las posibles coordinaciones existentes, y en las columnas las características que deben cumplir los criterios de determinación de la coordinación:

\section{Matriz de coordinación eficiente}

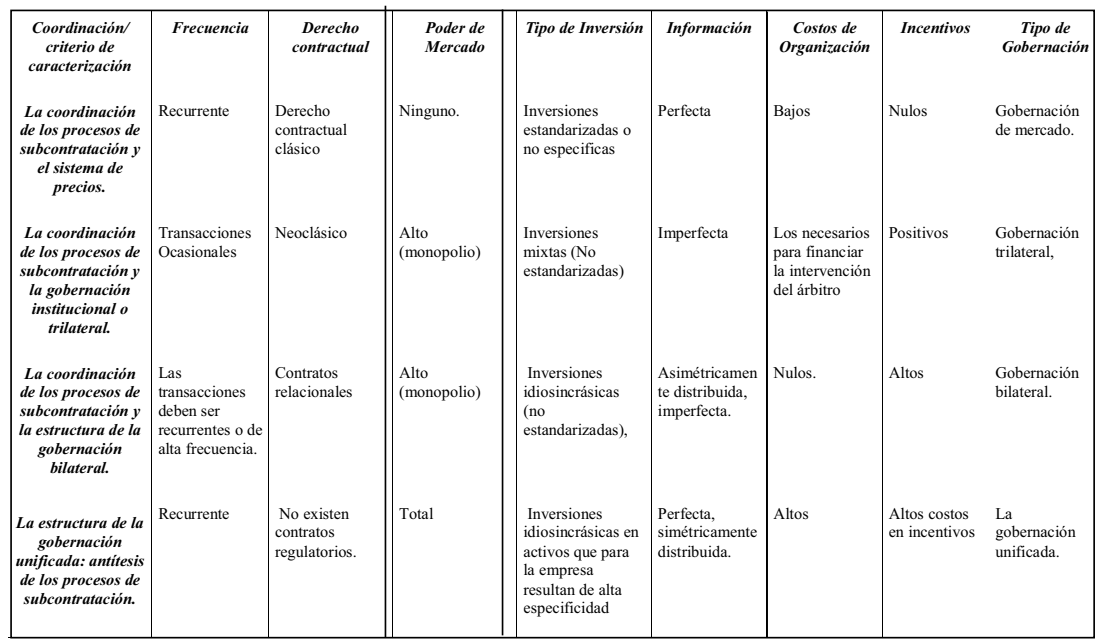

A partir del Cuadro N..$^{\circ}$, se desprende lo que aquí se llamará ruta eficiente del proceso de contratación. Ésta es una estrategia de modelación con la que se pretende mostrar los diferentes pasos que debe seguir un decisor en una empresa en el momento de subcontratar una actividad que realizaba la empresa y se desea eva- luar la factibilidad de tercerizarla o subcontratarla. En la teoría de la economía de las organizaciones se reconocen que cada una de las formas de gobernación de los recursos implica una y sola una ruta en el árbol de decisión que es posible seguir en el proceso de subcontratación; en lo que sigue se muestran cada una de la ruta factible. 
1.) La ruta eficiente de un proceso de subcontratación gobernada por el mercado

Aquí se presenta la ruta eficiente que debe seguir un proceso de subcontratación gobernado por el siste- ma de precios; para este fin se muestra la Gráfica N. ${ }^{\circ} 1$, el cual tiene forma de árbol de decisión e inicia en la raíz con el tipo de inversión, ésta debe ser no específica o estandarizada.

\section{Inversión no específica}

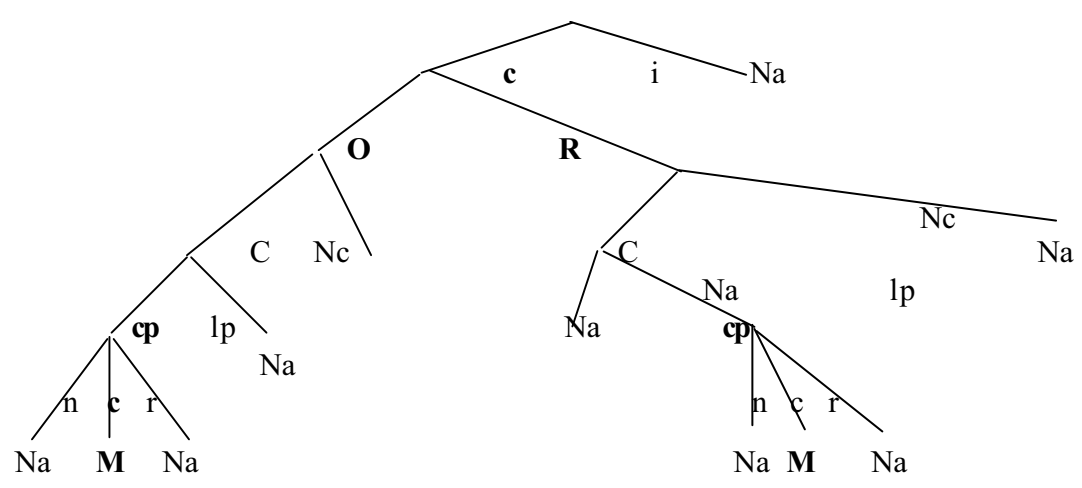

Gráfica N ${ }^{\circ}$ 1. Elaboración propia

El análisis de la ruta eficiente es metodológicamente parecida a un juego de inducción hacia atrás; el decisor debe analizar la actividad a subcontratar, y constatar que la inversión que realizará el proveedor es no específica o estandarizada; la ruta del árbol de decisión impone que se elimine la incertidumbre esto implica verificar que la negociación se efectuara en condiciones de certeza absoluta; el analista decisor, ha de tener en cuenta la frecuencia con que se demandará el bien o servicio objeto de subcontratación, si la inversión es estandarizada, la frecuencia de demanda puede ser recurrente u ocasional que en ambos casos funciona relativamente bien el sis- tema de precios; esto se evidencia en el árbol porque la rama se bifurca en transacción ocasional (O) y recurrente (R); luego el decisor debe constatar que existe un gran número de proveedores para reconocer que el mercado es competitivo (C), por tanto el no competitivo(Nc) no se tiene en cuenta. Como estamos ante una situación competitiva, la provisión del servicio requiere de un contrato de corto plazo (cp); en consecuencia el tipo de contrato jurídico que mejor se ajusta a ésta transacción es el clásico (c). Una vez que el decisor ha constatado todo lo anterior debe garantizar que el proceso de subcontratación sea gobernado por el mercado (M).Esto implica que la 
empresa subcontratista debe confiar en las bondades del mercado para abastecerse del bien o servicio objeto de subcontratación.

2.) La ruta eficiente de un proceso de subcontratación de gobernación trilateral

La gobernación trilateral se presenta en aquellos casos donde es necesario proteger la subcontratación a través de órganos de arbitraje y monitoreo, con el fin de apoyar el sistema de precios.
La ruta eficiente que debe seguir un proceso de subcontratación de gobernación trilateral se muestra a través de la Gráfica N. ${ }^{\circ}$ 2, la cual representa un árbol donde éste tipo de gobernación es posible tanto para el caso cuando la inversión es mixta, como para cuando la inversión es idiosincrásica y dado que la ruta que se sigue es la misma, éste inicia en un mismo nodo, con un tipo de inversión mixta e idiosincrásica.

Inversión mixta

Inversión idiosincrásica

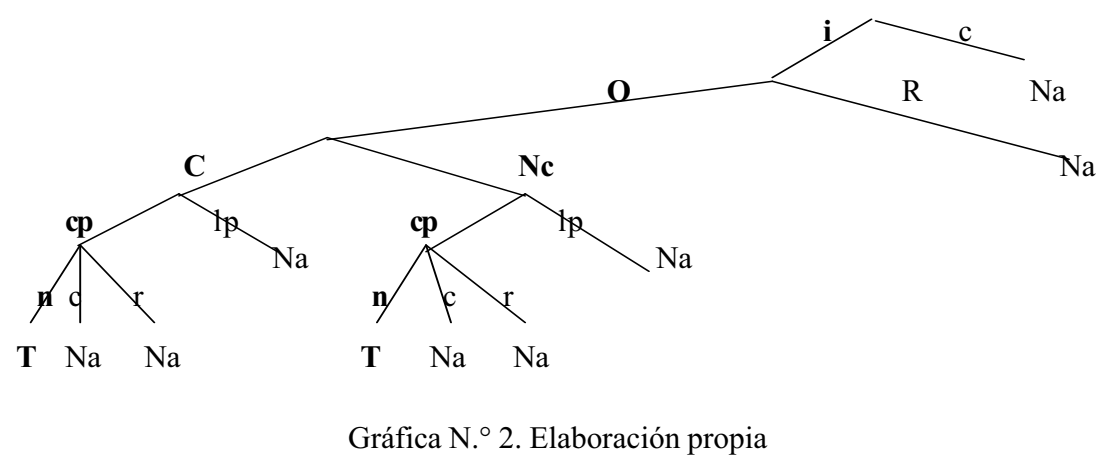

El Decisor debe analizar la actividad a subcontratar y verificar si la naturaleza de la inversión es mixta ó idiosincrásica, el decisor debe reconocer que ante estas dos clases de inversión la transacción está rodeada de incertidumbre; una condición básica para aplicar la gobernación trilateral es que la demanda del bien o servicio a subcontratar sea discontinua u ocasional,; el decisor para continuar el análisis ha de consultar las condiciones competitivas

del mercado, para seguir una ruta eficiente el decisor puede ser indiferente si el mercado es competitivo o no, esto se revela en el hecho que la rama se bifurca. El paso que sigue es establecer el tiempo de duración y dado que estamos ante una transacción de frecuencia ocasional, se requiere de un contrato de corto plazo; en consecuencia conviene establecer un contrato neoclásico (n), el cual debe ser de gobernación trilateral (T); en la que además de los 
tribunales se requiere un experto en la materia objeto del contrato para dirimir cualquier tipo de conflicto o disputa por ejemplo si lo que se está transando es un programa informático, un contrato de carácter neoclásico debe reflejar en sus cláusulas que ante cualquier anomalía de las partes se acudirá a un técnico o ingeniero de sistemas.

\section{3.) La ruta eficiente de un proceso} de subcontratación de gobernación bilateral

Esta es necesaria cuando en la negociación se configura una relación de monopolio bilateral, entre comprador y vendedor, para evitar los costos derivados del oportunismo, adaptación, monitoreo y búsqueda. La ruta eficiente que debe seguir un proceso de subcontratación de gobernación bilateral se muestra a través de la Gráfica $\mathrm{N} .^{\circ} 3$, la cual inicia en un mismo nodo con un tipo de inversión mixta o idiosincrásica, dado que en los dos casos la ruta a seguir es la misma.

Cuando la inversión es mixta o idiosincrásica, estos tipos de inversión siempre están rodeados por la incertidumbre y como este proceso de subcontratación requiere de transacciones continuas, debe seguirse la ruta de la frecuencia recurrente, luego se examina la condición del mercado, el cual aplica tanto para el caso competitivo, como para el no competitivo y dada la naturaleza de la frecuencia de la transacción, debe seguirse un proceso de subcontratación mediante un contrato de largo plazo (lp), a través de un contrato relacional (r), este tipo de subcontratación estará coordinada por una gobernación bilateral (B), la cual se caracteriza porque las partes diseñan un contrato amplio de tal forma que puedan ajustarse a las condiciones cambiantes de la economía.

\section{Inversión mixta e Inversión idiosincrásica}

$\mathrm{O}$

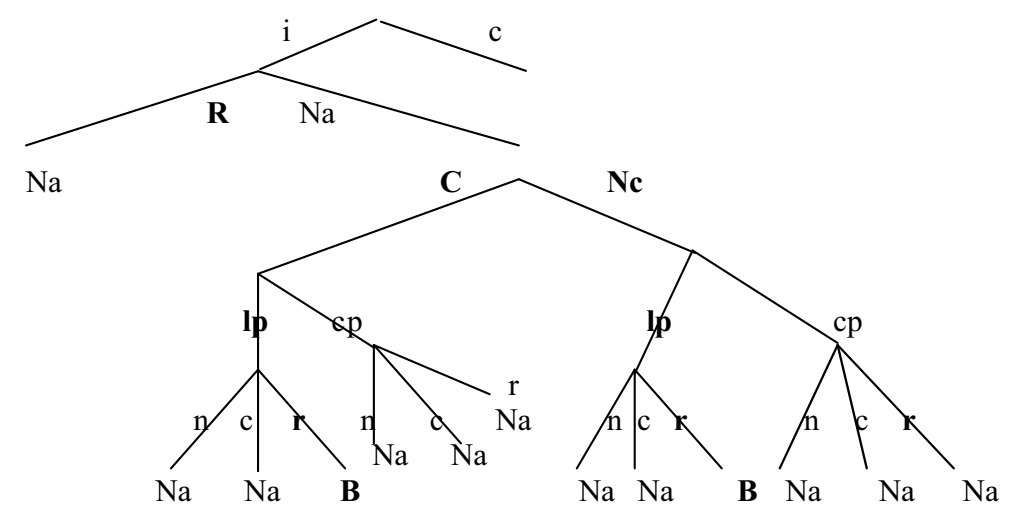

Gráfica N. ${ }^{\circ}$ 3. Elaboración propia 
Para saber si aplicar una estructura de gobernación bilateral, el decisor de la empresa contratante debe analizar si la actividad a subcontratar le demanda al proveedor una inversión mixta o idiosincrásica; en estos tipos de inversión siempre están rodeados por la incertidumbre y como este proceso de subcontratación requiere de transacciones continuas, debe seguirse la ruta de la frecuencia recurrente, luego se examina la condición del mercado, el cual aplica tanto para el caso competitivo, como para el no competitivo y dada la naturaleza de la frecuencia de la transacción, debe seguirse un proceso de subcontratación mediante un contrato de largo plazo (lp), a través de un contrato relacional (r), este tipo de subcon- tratación estará coordinada por una gobernación bilateral (B), la cual se caracteriza porque las partes diseñan un contrato amplio de tal forma que puedan ajustarse a las condiciones cambiantes de la economía.

4.) La ruta eficiente de un proceso productivo coordinado por una estructura de gobernación unificada.

La gobernación unificada se presenta cuando la mejor alternativa es realizar o producir la actividad dentro de la empresa.

La ruta eficiente que debe seguir un proceso de subcontratación de gobernación unificada se muestra a través de la Gráfica N. ${ }^{\circ} 4$, la cual inicia con un tipo de inversión idiosincrásica.

\section{Inversión Idiosincrásica}

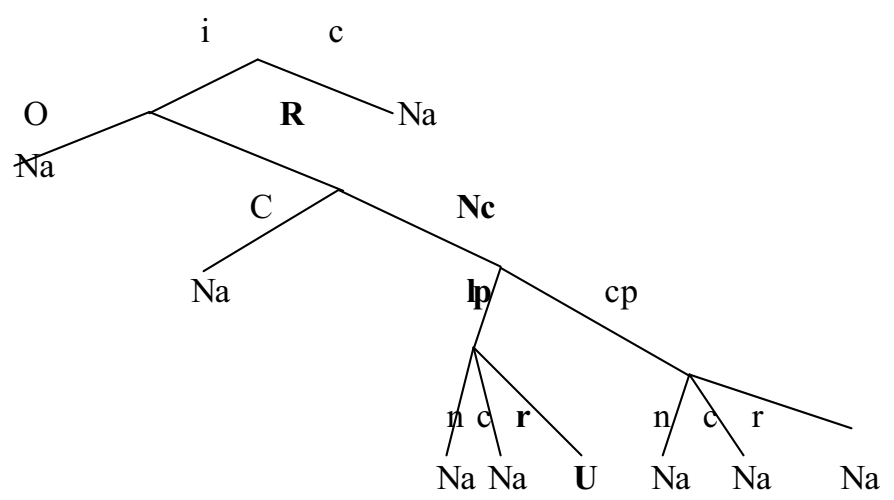

Gráfica N. ${ }^{\circ}$ 4. Elaboración propia

Cuando la transacción requiere de una inversión idiosincrásica, implica que debe reconocerse que la transacción está rodeada por la incertidum- bre, pues las inversiones de éste tipo involucran bienes de alta complejidad tecnológica. El paso siguiente en la ruta es establecer la frecuencia, para 
que amerite una gobernación unificada, la transacción tiene que ser de alta frecuencia o recurrente, por tanto no aplica la gobernación unificada para transacciones de frecuencia ocasional, luego es necesario examinar la cantidad de proveedores, debe reconocerse que el bien objeto de análisis es de alta complejidad tecnológica y especificidad de activos, por consiguiente si se busca el bien en el mercado se entrará en una situación de monopolio unilateral; es este hecho el que elimina la subcontratación o outsorsing, en la medida que la transacción sea recurrente, la empresa deberá ampliar su estructura productiva para proveerse del bien o servicio objeto de análisis, por tanto debe establecerse una gobernación unificada (U).

La importancia de seguir la ruta eficiente, radica en la posibilidad que disponen los decisores de diseñar un contrato que responda a los procesos de decisión que comprende la subcontratación. Partiendo de la hipótesis central de la economía de las organizaciones de Williamson y Coase, en la que se afirma que los contratos de bienes y servicios son intrínsecamente incompletos; conocer la ruta eficiente y diseñar el contrato siguiendo los pasos lógicos en el árbol de decisión, puede ayudar a contrarrestar el oportunismo de los agentes en una negociación y con ello disminuir los costos de transacción. Esto presupone que es posible asignar a las transacciones una estructura de gobernación, con lo que se garantiza que se ejecute en condiciones de eficiencia económica; además que es factible clasificar a las transacciones en el proceso de subcontratación. En esa perspectiva en el presente trabajo se entenderá por bien diseñado aquel contrato que mejor se ajuste a la ruta eficiente que le corresponda una vez reconocida la actividad a subcontratar; lo contrario es necesariamente cierto, un contrato se considerará como mal diseñado cuando una vez reconocida la actividad a subcontratar se sigue un procedimiento que desvía la transacción de la ruta eficiente que le corresponde.

\section{Marco Metodológico}

La población objeto de estudio son todos los contratos firmados desde el año 2001 hasta el año 2004. Los datos se obtuvieron en el archivo de la empresa llegando a un acumulado de 1488 contratos los cuales fueron divididos por la respectiva gerencia y año de formulación. Ésta información se encuentra presentada en el siguiente cuadro (Cuadro N. ${ }^{\circ}$ 2) 


\begin{tabular}{|c|c|c|c|c|c|}
\hline \multirow[b]{2}{*}{ GERENCIA } & \multicolumn{4}{|c|}{$\overline{\mathbf{A N O}}$} & \multirow{2}{*}{$\begin{array}{c}\text { TOTAL } \\
\text { Según gerencia }\end{array}$} \\
\hline & 2001 & 2002 & 2003 & 2004 & \\
\hline Gerencia general & 15 & 21 & 33 & 54 & 123 \\
\hline Gerencia de telecomunicaciones & 82 & 64 & 76 & 75 & 297 \\
\hline Gerencia de energía & 70 & 95 & 68 & 89 & 322 \\
\hline Gerencia de acueducto y alcantarillado & 67 & 74 & 61 & 152 & 354 \\
\hline Gerencia financiera & 11 & 16 & 25 & 70 & 122 \\
\hline Gerencia de informática & 23 & 31 & 20 & 26 & $\mathbf{1 0 0}$ \\
\hline Gerencia administrativa & 0 & 10 & 16 & 39 & 65 \\
\hline Gerencia comercia 1 & 0 & 29 & 30 & 46 & 105 \\
\hline TOTAL según año268 & 340 & 329 & 551 & 1488 & \\
\hline
\end{tabular}

Cuadro N. ${ }^{\circ}$ 2. Número de contratos firmados entre Emcali y proveedores de bienes y servicios según gerencia, desde el año 2001 hasta el año 2004. Fuente: elaboración propia.

En la tabla se presenta un total de contratos según Gerencia para el período objeto de estudio, cuya clasificación es la siguiente: En la General se firmaron un total de 123 contratos; en la de Telecomunicaciones 297; el la de Energía 322; en la de Acueducto y Alcantarillado 354; en la Financiera 122; en la de Informática 100; en la Administrativa 65 y en la Comercial 105 contratos.

\section{Selección de la muestra}

Se utilizó como criterio el que los contratos pertenecieran a cada una de las gerencias, y de cada área se utilizó como criterio, el tipo de contrato, es decir, si era una concesión, prestación de servicio, orden de servicio o suministro.

Un contrato implica una Concesión, cuando se otorga la ejecución y explotación de determinada obra pública de infraestructura, o cuando se presta un determinado servicio público por un plazo establecido. Por otra parte, Cuando se contratan servicios como personal para: vigilancia, aseo y cafetería, reconexión y suspensión, detectar fraudes en el servicio de acueducto y alcantarillado, el manejo de inventario, el reparto de facturas de servicios públicos, apoyo en contabilidad, lectura de medidores, entre otros, se está realizando un contrato de Prestación de servicios.

Un contrato es una Orden de Servicio, cuando la empresa encarga servicios como: mantenimiento; desarrollo de módulos de soporte y documentación de aplicativos comerciales y administrativos; atender requerimientos especiales de la DIAN; reparación, mantenimiento y desarrollo de software; auditoria externa de estado financiero, entre otros.

Cuando la empresa contratista, le provee a la empresa contratante algún tipo de bien tangible como: baterías, cables telefónicos, medidores volumétricos, sulfato de aluminio, cal, partes para la actualización de red, equipo electrónico de seguridad, gasolina, computadores para estaciones de red, 
repuestos, entre otros, se está en presencia de un contrato de Suministros.

El número de contratos con que contará la muestra, fueron elegidos bajo los criterios propios de la teoría estadística, teniendo en cuenta el nivel de confianza para la investigación, la proporción de éxito, es decir, la información que se tiene sobre la verdadera proporción de los datos, el nivel de error permitido para la investigación y por supuesto, la población total ${ }^{3}$. Identificados los valores para estas variables, y aplicando el ajuste respectivo, se obtuvo que para una población de 1488 contratos, el tamaño óptimo de la muestra es de 170 contratos, y la investigación cuenta con un total de 198, por lo tanto puede decirse que se tiene una muestra significativa para realizar la inferencia estadística a la población.

La selección de los contratos se hizo de manera aleatoria. Primero se agruparon los contratos por gerencia y por tipo en grupos de ocho, utilizando la identificación que les da la empresa para luego ubicarlos en excel y utilizar la herramienta que éste programa ofrece en la generación de números aleatorios. Los resultados del proceso pueden observarse en cuadro número 3; ahí se encuentran caracterizados los 198 contratos de la muestra por gerencia y por tipo.

\begin{tabular}{|c|c|c|c|c|c|c|c|c|c|}
\hline & $\begin{array}{c}\text { GERENCIA DE } \\
\text { ACUEDUCTO } \\
\text { Y ALCANTA- }\end{array}$ & $\begin{array}{c}\text { GERENCIA } \\
\text { FINACIERA }\end{array}$ & $\begin{array}{c}\text { GERENCIA DE } \\
\text { ENERGIA }\end{array}$ & $\begin{array}{c}\text { GERENCIA } \\
\text { GENERAL }\end{array}$ & $\begin{array}{c}\text { GERENCIA DE } \\
\text { TELECOMUNI- } \\
\text { CACIONES }\end{array}$ & $\begin{array}{c}\text { GERENCIA } \\
\text { COMERCIA }\end{array}$ & $\begin{array}{c}\text { GERENCIA } \\
\text { ADMINIS- } \\
\text { TRATIVA }\end{array}$ & $\begin{array}{c}\text { GERCIA INFOR- } \\
\text { MÁTICA }\end{array}$ & $\begin{array}{c}\text { TOTAL } \\
\text { CONTRATOS } \\
\text { SEGÚN SU TIPO }\end{array}$ \\
\hline CONCESIÓN & & & & & & & & & \\
\hline 2001 & 0 & 0 & 0 & 0 & 0 & 0 & 0 & 0 & 0 \\
\hline 2002 & 0 & 0 & 0 & 0 & 0 & 0 & 0 & 0 & 0 \\
\hline 2003 & 0 & 0 & 0 & 0 & 0 & 0 & 0 & 0 & 0 \\
\hline 2004 & 0 & 0 & 0 & 0 & 0 & 0 & 0 & 0 & 0 \\
\hline $\begin{array}{c}\text { TOTAL } \\
\text { CONCESIÓN } \\
\text { PRESTACIÓN } \\
\text { DE SERVICIO }\end{array}$ & $\mathbf{0}$ & $\mathbf{0}$ & $\mathbf{0}$ & $\mathbf{0}$ & $\mathbf{0}$ & $\mathbf{0}$ & $\mathbf{0}$ & $\mathbf{0}$ & $\mathbf{0}$ \\
\hline 2001 & 3 & 0 & 1 & 1 & 2 & 0 & 0 & 0 & 7 \\
\hline 2002 & 3 & 0 & 1 & 3 & 1 & 2 & 1 & 1 & 12 \\
\hline 2003 & 0 & 3 & 1 & 2 & 3 & 3 & 0 & 2 & 14 \\
\hline 2004 & 2 & 0 & 4 & 5 & 4 & 0 & 0 & 1 & 16 \\
\hline $\begin{array}{c}\text { TOTAL } \\
\text { PRESTACIÓN } \\
\text { DE SERVICIO } \\
\text { ORDEN DE } \\
\text { SERVICIO }\end{array}$ & $\mathbf{8}$ & $\mathbf{3}$ & $\mathbf{7}$ & $\mathbf{1 1}$ & $\mathbf{1 0}$ & $\mathbf{5}$ & $\mathbf{1}$ & $\mathbf{4}$ & $\mathbf{4 9}$ \\
\hline
\end{tabular}

3 no = Tamaño de la muestra; $p=$ Proporción real estimada de éxito; $q=1-p$ Proporciones; $d=$ Error muestral permitido, es decir, la; cantidad de error que se está dispuesto a aceptar al estimar la proporción real. $Z$ = Nivel de confianza deseado en la estimación. Como no hay información disponible en los datos pasados acerca de la proporción verdadera de contratos, se estableció $p=0.5$; tenemos que $Z=1,645$ para un nivel de confianza del $90 \%$ y $d=6 \%=0.06$ 


\begin{tabular}{|c|c|c|c|c|c|c|c|c|c|}
\hline 2001 & 10 & 2 & 2 & 5 & 12 & 6 & 0 & 4 & 41 \\
\hline 2002 & 10 & 5 & 6 & 2 & 8 & 2 & 0 & 2 & 35 \\
\hline 2003 & 5 & 0 & 5 & 4 & 3 & 0 & 1 & 1 & 19 \\
\hline 2004 & 5 & 0 & 3 & 0 & 1 & 0 & 0 & 4 & 13 \\
\hline $\begin{array}{c}\text { TOTAL } \\
\text { ORDEN DE } \\
\text { SERVICIO } \\
\text { SUMINISTRO }\end{array}$ & $\mathbf{3 0}$ & $\mathbf{7}$ & $\mathbf{1 6}$ & $\mathbf{1 1}$ & $\mathbf{2 4}$ & $\mathbf{8}$ & $\mathbf{1}$ & $\mathbf{1 1}$ & $\mathbf{1 0 8}$ \\
\hline 2001 & 0 & 0 & 6 & 0 & 4 & 0 & 0 & 0 & 10 \\
\hline 2002 & 4 & 0 & 3 & 2 & 7 & 0 & 5 & 2 & 23 \\
\hline 2003 & 1 & 0 & 2 & 0 & 1 & 0 & 1 & 0 & 5 \\
\hline 2004 & 0 & 0 & 1 & 0 & 2 & 0 & 0 & 0 & 3 \\
\hline $\begin{array}{c}\text { TOTAL } \\
\text { SUMINISTRO }\end{array}$ & $\mathbf{5}$ & $\mathbf{0}$ & $\mathbf{1 2}$ & $\mathbf{2}$ & $\mathbf{1 4}$ & $\mathbf{0}$ & $\mathbf{6}$ & $\mathbf{2}$ & $\mathbf{4 1}$ \\
\hline $\begin{array}{c}\text { TOTAL } \\
\text { CONTRATOS } \\
\text { EN CADA } \\
\text { GERENCIA }\end{array}$ & $\mathbf{4 3}$ & $\mathbf{1 0}$ & $\mathbf{3 5}$ & $\mathbf{2 4}$ & $\mathbf{4 8}$ & $\mathbf{1 3}$ & $\mathbf{8}$ & $\mathbf{1 7}$ & $\mathbf{1 9 8}$ \\
\hline
\end{tabular}

Cuadro N. ${ }^{\circ}$ 3. Clasificación de los contratos según: gerencia, tipo de contrato y año. Fuente: elaboración propia.

En la anterior tabla se puede observar que de los contratos seleccionados, no hay alguno que sea de concesión. En el caso de los contratos que son Prestación de Servicio, se obtuvo un total de 49, de los cuales 8 fueron ordenados por la Gerencia de Acueducto y Alcantarillado, 3 por la Financiera, 7 por la de Energía, 11 por la General, 10 por la de Telecomunicaciones, 5 por la Comercial, 1 por la Administrativa y 4 por la de Informática. La clasificación según el año fue la siguiente: para el año 2001 quedaron seleccionados 7 contratos; año 2002 , 12; año 2003, 14 y para el año 2004, 16 contratos.

En el caso de los contratos que son Órdenes de Servicio, se obtuvo un total de 108, de los cuales 30 fueron ordenados por la Gerencia de Acueducto y Alcantarillado, 7 por la Financiera, 16 por la de Energía, 11 por la General, 24 por la de Telecomunicaciones, 8 por la Comercial, 1 por la Administrativa y
11 por la de Informática. La clasificación según el año fue la siguiente: para el año 2001 quedaron seleccionados 41 contratos; para el año 2002, 35 contratos; año 2003, 19 contratos y para el año 2004, 13 contratos.

En el caso de los contratos que son Suministro, se obtuvo un total de 41, de los cuales 5 fueron ordenados por la Gerencia de Acueducto y Alcantarillado, 12 por la de Energía, 2 por la General, 14 por la de Telecomunicaciones, 6 por la Administrativa y 2 por la de Informática. La clasificación según el año fue la siguiente: para el año 2001 se seleccionaron 10 contratos; año 2002, 23; año 2003, 5 y para el año 2004 , 3 contratos.

En la tabla también se puede observar que al sumar el total de contratos en cada gerencia y el total de contratos en cada año, se obtiene el mismo resultado; por ejemplo en el caso de los contratos clasificados como Prestación de Servicio, la suma del total de contratos 
en cada área da como resultado 49 , que es igual a la suma de contratos en cada año. Tenemos también que el total de contratos (de Concesión, Prestación de Servicio, Orden de Servicio y suministro) en cada gerencia da como resultado 198 contratos que es igual al total de contratos, según su tipo (suma del total de contratos de Concesión, Prestación de Servicio, Orden de Servicio y Suministro)

\section{Modelo de ruta eficiente en el pro-} ceso de subcontratación

Dado que uno de los objetivos específicos de la investigación es identificar una metodología para detectar cuándo un contrato está bien o mal diseñado, se ha planteado un modelo mediante la metodología de la ruta eficiente que permite identificar cuál es la ruta que debe seguir un proceso de contratación para garantizar la eficiencia, es decir, el de menor costo de contratación para culminar el proceso de negociación.

Para la realización de ésta teoría se tomó como base el modelo tipo grafos o diagrama de árbol. "Un árbol de decisión es una herramienta gráfica para mostrar la secuencia de alternativas de decisión y de los sucesos que intervienen en la toma de decisiones en situaciones de incertidumbre" 4 , por lo tanto si el problema de decisión es complejo, el árbol resulta ser muy útil porque le permite al decisor organizar la información, estableciendo el orden en que se toman las decisiones y en que ocurren los sucesos, así podrá llegar a conclusiones certeras respecto al proceso de contratación.

\section{El modelo de regresión logística}

Para el tratamiento de la información se utilizó un modelo de Regresión Logística también conocido como Análisis Logístico, es una variante de los modelos de análisis discriminante cuando sólo se tienen dos grupos bien diferenciados.

La Regresión Logística se propone obtener un modelo determinado de Regresión Múltiple, el cual presenta las siguientes características:

- La variable dependiente no es continua, sino discreta y binaria

- Las variables explicativas pueden ser cuantitativas y/o cualitativas

- La ecuación del modelo no es una función lineal, sino exponencial

Debe prestarse especial atención a las variables que constituyen el modelo a través de estas se cumplen dos propósitos: en primer lugar recoger los elementos que constituyen el diseño de un contrato, en segundo término, en el contexto de este trabajo evaluar la habilidad de los hacedores de contratos en Emcali.

La Variable dependiente en el modelo es el ÍNDICE DE RIESGO DEL DISEÑO DEL CONTRATO, con esta variable se trata de medir el riesgo de que un contrato esté bien o mal diseñado, de tal manera que se prevean las con-

4 Bierman Harold, Charles P. Bonini. Análisis Cuantitativo para la toma de decisiones. Octava edición. Editorial Addison-Wesley Iberoamericana, S.A.1994. 
tingencias y se eviten los posibles costos de transacción ex post y ex ante en la negociación. La variable está constituida por los siguientes elementos del contrato:

Numero de Compromisos estipulados en el objeto del contrato (CO), Ejecutor de la inversión (EI), Exclusividad o posibilidad de ceder el negocio a terceros, (EXC), Riesgo en la prestación del servicio que involucra la reputación del contratista (RPS), Derechos de propiedad (DP), Eventos aleatorios (EVAL), Solución de diferencias (SOLDIF), Problemas de ejecución (PE), Diseño del contrato (DC). Se asignó un valor a cada uno de estos elementos Si la sumatoria da un valor mayor o igual a 6 , la variable dependiente toma el valor de 1 y si dicha sumatoria es menor de 6 , toma el valor de 0 , por tanto, esta variable es dicotómica, pues toma el valor de 1 si el contrato es sensible a experimentar costos de transacción y toma el valor de 0 en el caso contrario.

Se espera entonces que la variable dependiente discrimine los contratos, de tal forma que los mal diseñados sean los que tengan mayor índice de riesgo y los mejor diseñados sean los de menor valor.

Variables independientes. El análisis de subcontratación inicia con la evaluación de la inversión y el objeto del contrato, por consiguiente la primera variable es el Valor de la inversión (LN) Es el valor monetario de la transacción. Continúa con una revisión de las condiciones de incertidumbre y la frecuencia de la transacción, esto se trata de captar con la variable RIESGO DE EJECUCIÓN
DEL CONTRATO; con la cual se trata de verificar que los hacedores de los contratos en Emcali, toman las precauciones necesarias para disminuir el grado de incertidumbre que suele rodear todo proceso de subcontratación; como componentes de esta variables entran los siguientes elementos del contrato: Funciones del supervisor (FS); Delegación que capta el hecho de que la empresa demanda un servicio teniendo facultades para proveérselo internamente, (DEL); Cesión del contrato mediante la cual se evalúa si el proveedor durante el periodo de contratación se dio a terceros el contrato (CSC); Subcontratación múltiple, aquí se analiza si en un mismo periodo la empresa subcontrató a dos o mas proveedores para una misma tarea (SUBC), especificación del objeto (E.O); Régimen de asignación del contrato, mediante este elemento se evalúa si la actividad a subcontratar implica una demanda continua u ocasional, (RAC), Adición de valor al contrato (ADVC) y Diseño del contrato (DC). A cada uno de los elementos se le asigna un valor de tal manera que a mayor valor se infiere mayor riesgo en la ejecución del contrato y a menor valor se le asocia menor riesgo.

La fase siguiente en un proceso de subcontratación continúa con la evaluación del mercado, en este trabajo este elemento se capta a través del número de empresas que participan la adjudicación de un contrato o licitación, (E.1).

La evaluación del proceso de subcontratación continúa con el tiempo o periodo de duración del contrato, este fenómeno en el contrato se mide a tra- 
vés del periodo de contratación, aquí denominada como duración del contrato (D.C)

El paso siguiente en el proceso de subcontratación es ajustar el contrato a las leyes vigentes y demás disposiciones internas de la empresa, este fenómeno se analiza mediante la variable RIESGO LEGAL, entran en esta categoría: especificación de los Derechos del contratista (DCTS); estipulación de los derechos del contratante (DCTT); manifiesta expresa de quién es el Ejecutor de la cláusula penal (ECLAP); estipulación explícita de una cláusula de Perfeccionamiento del contrato (PERF); existencia de una cláusula de Revisión del contrato (REV); número de Causas de terminación (CT); inclusión de cláusulas en las que se especifique como se solucionarán las diferencias (SOLDIF); especificación de leyes, decretos y resoluciones que respaldan el contrato, Relación legal (REGLE); y número de las obligaciones de las partes del contrato (OBLI. Se asigna un valor a cada uno de estos elementos (en muchos 0 o 1) y se constituye un índice de riesgo legal, este mide la posibilidad legal que tienen las partes de no cumplir a cabalidad el contrato.

La última fase del análisis de un proceso de subcontratación es establecer el aseguramiento del contrato, entran en esta categoría los siguientes componentes: Tiempo de la garantía en meses (TGAR). Valor pólizas (VPOLIZAS): suelen considerarse en el contrato las pólizas: de cumplimiento, de responsabilidad civil extracontractual y calidad de estudios realizados. Valor de la multa (LN VALOR MULTA): Es el valor que se cobra en el caso de incumplimiento.

Una vez definidas las variables independientes y la dependiente, la función esperada era la siguiente:

$$
\begin{gathered}
Z=\beta_{0}+\beta_{1} X_{1}+\beta_{2} X_{2}+\beta_{3} X_{3}+\beta_{4} X_{4}+ \\
\beta_{5} X_{5}+\beta_{6} X_{6}+\beta_{7} X_{7}+\beta_{8} X_{8}+\beta_{9} X_{9}
\end{gathered}
$$

Donde:

$Z$ es la variable dependiente, es decir, el Índice de riesgo de diseño del contrato.

$\beta_{0}$ es el intercepto a estimar y,

$\beta_{1,} \beta_{2,} \beta_{3,} \beta_{4,} \beta_{5} \beta_{6} \beta_{7} \beta_{8} \mathrm{y} \beta_{9}$ son los parámetros desconocidos a estimar de las variables independientes, $X_{1}, X_{2}, X_{3}$, $X_{4,} X_{5,} X_{6,} X_{7,} X_{8}$ y $X_{9}$ que corresponden a: El Tiempo de la garantía en meses (TGAR); Duración real del contrato (DRC) ; Empresas en licitación (EL); Duración del contrato (DURAC); Valor pólizas (VPOLIZAS); Valor de la inversión (LN VALOR CONTRATO); Valor de la multa (LN VALOR MULTA); RIESGO LEGAL y RIESGO DE EJECUCIÓN DEL CONTRATO respectivamente, es decir:

$$
\begin{aligned}
\text { DC Riesgo }= & \beta_{0}+\beta_{1} \text { TGAR }+\beta_{2} \text { DRC } \\
& +\beta_{3} \text { DURAC }+\beta_{4} \text { VPOLIZAS } \\
& +\beta_{5} \text { VPOLIZAS }+\beta_{6} \text { LN } \\
& \text { VALOR CONTRATO }+ \\
& \beta_{7} \text { LN VALOR MULTA }+ \\
& \beta_{8} \text { RIESGO LEGAL }+\beta_{9} \\
& \text { RIESGO DE EJECUCIÓN } \\
& \text { DEL CONTRATO }
\end{aligned}
$$




\section{El impacto del diseño contractual en la eficiencia de una organización pública: el caso de Emcali}

En esta sección se presenta el análisis de resultados derivado de la aplicación del modelo de regresión logística, y a través de éste se espera probar las hipótesis que inspiran el presente trabajo.

\subsection{Una metodología para la clasificación de los contratos con relación al diseño económico}

Este apartado tiene como fin, diseñar una metodología para determinar la probabilidad de que un contrato establecido entre Emcali y los proveedores de bienes y servicios, estén mal diseñados económicamente.

$\mathrm{Al}$ respecto se planteó la hipótesis específica de que "dado el marco de la ley 142 de 1994 de la cual Emcali formuló las resoluciones: GG001800 de Septiembre 20 del 2000 y la GG-000069 del 31 de Enero de 2003, las cuales regulan los contratos entre la empresa y los proveedores; en el presente trabajo se muestra que es posible construir una metodología para clasificar a los contratos, según su diseño; dicha metodología involucra factores que captan el impacto legal, mercantil, y organizacional que determinan la contratación entre Emcali y los proveedores. Una metodología para este propósito, como ya se dijo atrás se apoya en la técnica estadística Regresión logísti- ca, porque permite identificar y clasificar a los contratos en buenos y mal diseñados y los agrupa acorde a los factores de análisis, y además permite evaluar la probabilidad dado el conjunto de factores que un contrato experimente fallas y por consiguiente, costos de transacción".

Una revisión de los 198 contratos en función de la ruta eficiente planteada en los árboles de decisión en los que se evalúa la inversión, la incertidumbre, la competencia, la frecuencia, el derecho contractual y la gobernación eficiente, arrojó que los 198 contratos se pueden establecer dos grupos: el primero compuesto por 70 contratos bien diseñados, es decir, que en el proceso de decisión de subcontratación siguieron la ruta eficiente, y el segundo grupo lo constituyen 128 contratos mal diseñados, esto implica que en el proceso de outsourcing se desviaron de la ruta eficiente (resultado que se mostrará más adelante en el Cuadro N. ${ }^{\circ}$ 5). Se infiere implícitamente que por cada contrato bien diseñado hay aproximadamente dos mal diseñados.

Para encontrar la probabilidad de que un contrato esté mal diseñado se calculó un modelo de regresión logística. Al estimar la función $\mathrm{Z}$ a partir de las variables seleccionadas por el modelo, se obtuvo lo siguiente:

DC Riesgo $=-0.410$ LN VALOR CONTRATO + 0.354 RIESGO EJECUCIÓN CONTRATO + 0.101

Donde:

-0.410 y 0.354 son los valores correspondientes a los parámetros $\beta_{6} \mathrm{y}$ 
$\beta_{9}$ de las variables LNVALORCONTRATO Y RIESGOEJECUCIÓNCONTRATO, mientras que 0.101 es el valor del parámetro del intercepto, el cual significa que independientemente de cualquier variable hay un riesgo positivo en la ejecución de un contrato, es decir, todo contrato es intrínsecamente incompleto. Con respecto a las dos variables de decisión que entran en el modelo -LNVALORCONTRATO Y RIESGOEJECUCIÓNCONTRATO- debe decirse que el contrato es más riesgoso cuanto más incidencia tengan las variables que componen el índice de ejecución, esto es, entre mayores sea la incidencia que tengan sobre los contratos los Compromisos del objeto (CO), el ejecutor de la inversión (EI), la Exclusividad (EXC), el Riesgo en la prestación del servicio (RPS), los Derechos de propiedad (DP), los Eventos aleatorios (EVAL), la Solución de diferencias (SOLDIF), los Problemas de ejecución (PE) y el Diseño del contrato (DC). Con respecto al logaritmo del valor del contrato, cuanto mayor sea el valor del contrato, menor es la probabilidad de que el contrato sea incompleto, lo cual puede atribuirse al hecho que un mayor monto de la inversión de un contrato, implica un mayor control fiscal, razón por la cual los hacedores de contratos tomarán más precauciones en su diseño y ejecución.

El modelo de árboles de decisión del cual se estableció la ruta eficiente involucra varias variables que pueden medirse estadísticamente, y que en teoría deben ser variables clasificatorias de los contratos entre aquellos bien y mal diseñados.
Esto implica que son tan importantes las variables que entran a ser parte del modelo y clasifican a los contratos en los dos grupos, como encontrar las razones para que aquellas que deben clasificar los contratos no logran tal objetivo.

\subsubsection{Variables que clasifican los contratos entre Emcali \\ y sus proveedores}

Como se mostró en la función $\mathrm{Z}$ de la regresión logística, las variables que mejor clasifican a los contratos entre aquellos bien diseñados y los que experimentan fallas son: $\ln$ del valor del contrato y el riesgo de ejecución del contrato.

\section{La importancia del valor de la in- versión en el diseño contractual}

El monto de la Inversión es clasificatorio porque a partir de un análisis de los resultados se observó que en los contratos cuyo monto en la inversión es mayor, hay mayor probabilidad de que se presenten alianzas entre empresas oferentes, lo cual aumenta las posibilidades de que se haga una mala selección, porque la empresa elegida, aunque fuera aquella que presentó unos costos menores puede no arrojar los mejores resultados en cuanto a la calidad del bien o servicio ofrecido.

Retomando la ruta eficiente conjuntamente con el modelo estadístico, la anterior afirmación conduce también a que se pueden tener tendencias explícitas respecto a la estructura de mercado, pues dependiendo del número de empresas en licitación, se observó que a mayor monto de la inversión, las pro- 
babilidades de que se de una relación de monopolio o duopolio son mayores.

\section{Riesgo de ejecución del contrato}

El riesgo de ejecución es una variable clasificatoria porque intenta captar el riesgo en que se incurre en el proceso de ejecución de un contrato.

\section{Número de Compromisos}

Es riesgoso para un contrato el número de número de compromisos, porque entre más compromisos implique el objeto, más costoso es negociar un contrato, dado que el ambiente se hace más complejo, por lo tanto la probabilidad de que un contrato sea incompleto es mayor, lo cual llevaría a adoptar mecanismos contra el oportunismo, con el fin de disminuir ineficiencias que reduzcan la calidad de los servicios prestados por la empresa. Refiriéndonos a lo que plantea Gorbaneff (2002, Pág. 13), se podría decir que el hecho de que el ambiente sea más complejo, hace que los agentes traten de ahorrar los costos de transacción exante y por lo tanto disminuyen la completitud.

\section{Adición de valor del contrato}

Una variable importante para determinar el riesgo en la ejecución de un contrato es la posibilidad de adicionar el valor del contrato; a este respecto se abren incentivos a una conducta oportunista en razón a la incompletitud intrínseca de todos los contratos; en virtud de este problema, lo relevante no es el precio de la oferta, ni la capacidad técnica, sino la reputa- ción del contratista, dado que esto podría establecer un ambiente de cooperación.

\section{Diseño del contrato}

El diseño del contrato es una variable relevante dentro del riego de ejecución del contrato, porque el análisis de ésta implica también el análisis de la frecuencia y el monto de la inversión, porque en conjunto estas dos determinan la mejor estructura de gobernación del contrato. Cuando la gobernación del contrato no corresponde a la que debiera ser, dada la frecuencia y la inversión, se dice que el contrato está mal diseñado, es decir, está incompleto y en el caso contrario, cuando la gobernación del contrato corresponde a la que debiera ser, se dice que el contrato está bien diseñado.

4.1.2 Las variables que no clasifican a los contratos en Emcali

Como se dijo anteriormente, para un análisis de la eficiencia de una empresa son tan importante las variables que clasifican a los contratos entre bien y mal diseñados, como aquellas que no logran este propósito. En este documento las variables que no clasifican a los contratos son aquellas cuyo p- valor supera a 0.05 , porque esto implica que la variable no tiene significancia estadística para diferenciar los contratos entre los dos grupos de análisis: los bien diseñados y aquellos que presentan fallas. Un análisis de este último conjunto de variables no es relevante desde el punto de vista estadístico, pues al carecer de significan- 
cia no entran en el modelo. No obstante la confianza que se tenga en la técnica estadística, el hecho que una variable no entre significativamente en el modelo, implica que no está cumpliendo con el propósito para el que fue introducida en el contrato, que en términos económicos significa reducir los costos de transacción.

Las variables que no lograron clasificar los contratos son las siguientes:

- Tiempo de garantía en meses

- Duración del contrato

- Empresas en licitación

- Valor pólizas

- Riesgo legal

\subsection{Dificultades del diseño contractual en los procesos de outsourcing en Emcali}

En esta sección se demostrará que en la empresa Emcali existen contratos mal diseñados en el aspecto económico, esto implica que existe una diferencia entre en el diseño contractual a nivel económico y a nivel jurídico. Un contrato está bien diseñado legalmente cuando es conforme a las leyes que lo rigen y no es factible encontrar un contrato sin estas características dentro de una organización pública; no obstante el correcto diseño legal de un contrato, sí es factible que estos fallen en el reparto económico de los beneficios, esto es así porque no es posible prever todas las contingencias futuras que rodean un contrato, lo cual da pie al oportunismo de una de las partes.

Para evaluar si hay un mal diseño contractual en el aspecto económico en Emcali, es preciso identificar las actividades económicas susceptibles de subcontratación en esta organización, lo cual se presentará en el Cuadro N. ${ }^{\circ} 4$.

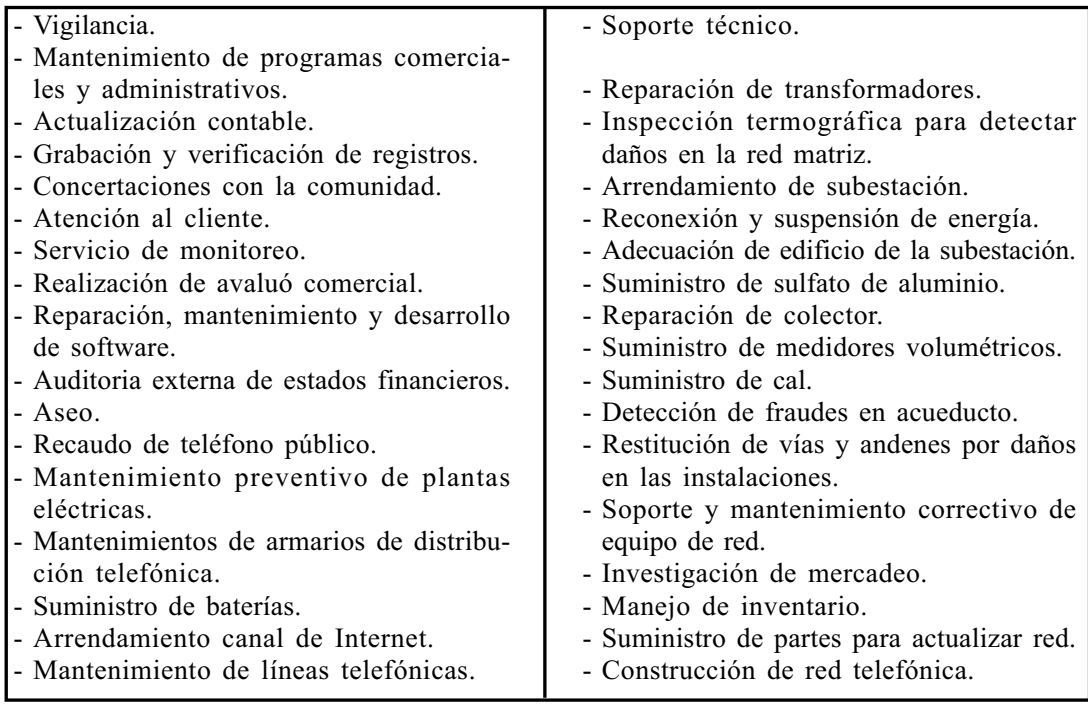




\begin{tabular}{|l|l|}
\hline - Alquiler de equipos para mejorar servicio & - Servicio de apoyo. \\
de Internet. & - Estudio de resistencia sísmica. \\
- Mantenimiento y restauración de equipo & - Suministro de módems. \\
de computo. & - Adecuación, reparación y mantenimien- \\
- Suministro de cables telefónicos. & to de edificios. \\
- Entrega de correspondencia. & - Suministro de equipo electrónico de se- \\
- Asesoría jurídica. & guridad. \\
- Limpieza de sumideros. & - Suministro de gasolina. \\
- Reparación de redes de alcantarillado. & - Adquisición de computadores. \\
- Cancelación de fraudes de acueducto. & - Soporte en red corporativa. \\
- Reparación de daños en la red matriz de & - Preparación y elaboración de declaracio- \\
acueducto. & nes de renta. \\
- Suministro de energía. & - Suministro de repuestos. \\
- Asesoria legal en contratación. & - Lectura de medidores. \\
- Orientación a clientes sobre el uso racio- & - Reparto de facturas de servicio público.- \\
nal del agua. & Fumigación de plantas. \\
- Determinación del valor de cada kw/h. & - Recuperación de equipos. \\
- Cambio de tuberías. & - Canalización y elaboración de cámaras. \\
- Atención de procesos jurídicos. & - Medición de calidad del agua. \\
\hline
\end{tabular}

Cuadro N. ${ }^{\circ} 4$ Actividades externalizadas por Emcali. Elaboración propia, con base en el objeto de los contratos analizados de la muestra.

En la anterior tabla se presentan las actividades que se subcontrataron, lo que se trata de demostrar es que en este proceso hubo contratos mal diseñados.

El Cuadro N. ${ }^{\circ} 5$ recoge información sobre el diseño contractual, éste se divide en 4 columnas y 5 filas; las filas muestran las estructuras de gobierno de los contratos: gobernación de mer- cado, trilateral, bilateral y unificada. Por su parte, en las columnas se presentan los contratos que fueron realizados, de aquellos los que estuvieron errados o bien diseñados según la ruta eficiente, y por último, aquellos que debieron ser coordinados por determinada estructura pero estuvieron erradamente ubicados dentro de otra gobernación

\begin{tabular}{|l|c|c|c|c|}
\hline & Realizados & Errados & Bien Diseñados & Necesarios \\
\hline Mercado & 119 & 86 & 33 & 53 \\
\hline Trilateral & 0 & 0 & 0 & 55 \\
\hline Bilateral & 79 & 42 & 37 & 80 \\
\hline Unificada & 0 & 0 & 0 & 10 \\
\hline Total & 198 & 128 & 70 & 198 \\
\hline
\end{tabular}

Cuadro N. ${ }^{\circ}$ 5: Fuente Elaboración propia 
En el cuadro se muestran los 198 contratos de la muestra. El estudio arroja que hubo un total de 128 contratos mal diseñados, mientras que en la tercera columna se observa que 70 contratos sí siguieron la ruta eficiente. En la última columna se presentan el número de contratos que debieron pertenecer a una estructura de gobernación específica para que fueran ejecutados eficientemente.

Para verificar que algunos contratos estuvieron mal diseñados, debe analizarse la estructura de gobernación de los contratos, lo cual implica observar el tipo de inversión, la frecuencia con que se realiza la transacción, la incertidumbre y el derecho contractual empleado, esto es, analizar la ruta eficiente de los árboles de decisión presentada en los gráficos 1, 2,3 y 4 .

Una vez revisados todos estos aspectos se encontró que de la muestra 119 contratos se elaboraron bajo la estructura de gobernación de mercado coordinada por el sistema de precios, de los cuales sólo 33 se encuentran bien diseñados dentro de esta estructura y otros 20 se encuentran en otras coordinaciones debiendo estar dentro de la estructura del sistema de precios, y 66 contratos están localizados dentro de una estructura de gobernación ineficiente. La revisión no arrojó ningún contrato diseñado dentro de la estructura de gobernación trilateral, sin embargo, el análisis de los contratos acorde al objeto, tipo de inversión y demás aspectos que deben tenerse en cuenta, 55 contratos del total de la muestra requieren de éste tipo de gobernación.
Al continuar la revisión de los contratos se encontró que 79 de ellos estuvieron diseñados bajo la coordinación de la gobernación bilateral, de los cuales 37 siguieron la ruta eficiente, los restantes 42 contratos estuvieron mal diseñados. El análisis de la muestra evidenció que 80 contratos requerían de la estructura bilateral, y dado que sólo 37 se efectuaron bajo esta ruta eficiente, hubo 43 contratos que debiendo pertenecer a la coordinación bilateral fueron celebrados en su gran mayoría bajo la estructura de gobernación de mercado

En la muestra se buscó si había actividades que merecían una estructura de gobernación unificada, es decir, actividades que no se debían subcontratar, sin embargo se encontró que en todas las actividades hubo subcontratación, cuando la ruta eficiente sugería que 10 procesos de los que fueron subcontratados debieron ser realizados directamente por la empresa y no encargar a otras entidades el suministro de esos servicios.

\subsubsection{Las Consecuencias del mal}

diseño de los contratos

La teoría sugiere que el problema central de un mal diseño contractual redunda en el surgimiento de costos de transacción; como se sabe estos costos se evidencian tanto en la etapa pre como en la post contractual. Cuando los contratos están mal diseñados en el aspecto económico aunque estén conforme a la ley, suelen encontrarse incentivos para actuar de manera oportunista. 
Un primer problema se halla en la carencia del soporte o total de documentación para dar inicio al contrato. Puede ocurrir que los contratos carezcan del estudio de oportunidad y el certificado de existencias, lo cual significa que han habido contratos en los que el supervisor no ha exigido el cumplimiento eficiente del mismo y por lo tanto, éste puede no llevarse a cabo en las condiciones y tiempo establecido, lo cual generará costos de transacción en forma de mala calidad de los materiales, ajustes en las pólizas de cumplimientos, prorrogas innecesarias, entre otros.

También puede suceder que no se exija la ejecución idónea y oportuna del objeto contratado; se contrata bajo precios desactualizados o por debajo de los precios de mercado y materiales de una calidad menor a la exigida; no se adelantan revisiones periódicas a las obras ejecutadas, servicios prestados o bienes suministrados, quedando en el limbo la certeza de si cumplen con las condiciones que fueron ofrecidas por los contratistas.

Una situación factible cuando los contratos están mal diseñados es la manipulación en la adjudicación del contrato; esto puede observarse mediante dos conductas típicas: la primera es encontrar errores en las propuestas, por pequeños que éstos sean (algo relativamente sencillo, dada la cantidad de requisitos que ellas incluyen), con el fin de declarar desierta la licitación en tantas oportunidades como sea necesario y proceder a asignarla por contratación directa a la fir- ma que ofrezca la comisión exigida. La segunda conducta oportunista podría encontrarse en asociaciones de contratistas para presentar las licitaciones, con el fin que el ganador quede dentro del grupo. Allí, varias empresas o contratistas se reparten los contratos, asegurándose su parte o acuerdan para quién va a ser el contrato de turno y los probables contratos futuros; para lo cual los contratistas o empresas licitantes que les toca esperar, entregarán en la propuesta unos presupuestos más elevados, para así garantizar que no serán elegidos en dicha ocasión.

En la etapa post-contractual se podrían presentar problemas como: $\mathrm{El}$ cobro de multas, incumplimiento de las garantías, aplazamiento del contrato, incumplimiento por parte del supervisor de sus funciones, entre otras.

Independientemente del tipo de contratación (directa o por licitación), el adjudicar un contrato para cubrir el requerimiento de una construcción o de mano de obra, bien sea calificada o no, son los que presentan un mayor número de costos de transacción.

\section{Análisis de la influencia del mal diseño de los contratos en la crisis financiera de EMCALI}

Esta parte tiene como finalidad, evaluar hasta qué punto la crisis financiera de la empresa tiene como una de las causas el mal diseño de los contratos.

Dado éste objetivo, se planteo la hipótesis de que "cuando los contratos en una empresa como Emcali expe- 
rimentan fallas en el diseño económico, se incurre en costos de transacción derivados de la dificultad en la elaboración y ejecución de los contratos, estos se manifiestan en: Costo de aseguramientos como pólizas y garantías, costos de incumplimiento que se evidencian en demandas e indemnizaciones, costos de sobre precio del valor del bien o servicio vendidos a la empresa, costos de desmejoramiento de la calidad de los bienes y servicios adquiridos por la empresa; todos estos costos afectan negativamente a la estructura de costo de la empresa y negativamente a la eficiencia, por consiguiente el mal diseño de los contratos en la medida que genere costos de transacción, afecta el funcionamiento y el logro de los objetivos de la empresa Emcali".

Cuando se analizaron los indicadores de gestión financiera de Emcali, se pudo observar que en el flujo de caja para el período 2000-2003, el porcentaje del déficit, en lo relacionado con proveedores y contratistas fue del $3,9 \%$ en el año $2000 ; 0,81 \%$ en el 2001 ; $2,2 \%$ en el 2002 y un costo del $51 \%$ en el $2003^{5}$. Por otro lado, la compra de energía representó un déficit del $20 \%$ para el $2000 ; 15,4 \%$ en el $2001 ; 0,16 \%$ en el 2002 y un costo del $0,62 \%$ en el 2003.

Para el año 2003, se le adeudaba a la empresa Publicar S.A. 1,4 mil millones, lo cual en el déficit representó un $0,03 \%$.

Tenemos entonces que el déficit correspondiente a contratación y proveedores, representó en el total el $23,79 \%$ para el $2000 ; 16,16 \%$ para el 2001 y $2,37 \%$ para el 2002 ,

En cuanto a los gastos generales para el período 2003-2004, se puede observar que las mayores variaciones correspondieron a: combustible y lubricantes, mantenimiento, sentencias y conciliaciones, fuerza eléctrica y uso de frecuencia, compra de equipos e impresos y publicaciones.

En cuanto a la calidad de los servicios se puede decir, que en el caso de la telecomunicación el porcentaje de daños reportados del 2002 al 2003, sólo disminuyó en un $8,4 \%$ y en un $0,4 \%$ del 2003 al 2004; en el caso del servicio de acueducto y alcantarillado, los daños disminuyeron en sólo en un 1,3\% del 2001 al 2002 y en un 8,4\% del 2002 al 2003, mientras que aumentaron el $27,99 \%$ del 2003 al 2004, lo cual se traduce en una alta ineficiencia y por tanto en un aumento en el índice de pérdi-

5 Como ya se había explicado en el apartado que trata acerca de los indicadores de gestión financiera de Emcali, para el período 2002-2003 no se presentó déficit, debido a que se aplicó la Resolución No. 562 de Febrero de 2003, provenida de la SSPD, que suspendió el pago a las acreencias adquiridas antes de la intervención de la empresa, razón por la cual al ser el saldo en caja-bancos mayor que las cuentas por pagar vencidas, la diferencia es positiva y el porcentaje correspondiente en las cuentas por pagar vencidas de la parte de proveedores y contratistas alto, en relación con el total que fue de $\$ 4834,5$, en el cual no se tuvieron en cuenta los $\$ 31148,8$, que corresponde al pago de las acreencias. 
das del $0,9 \%$; además éste período coincide con aquel en el que los gastos en compra de equipos y mantenimiento fueron mayores; en el caso del servicio de energía para el período 2000-2001 hubo ineficiencia al aumentar el índice de pérdidas en $2,91 \%$, al igual que en el período 2001-2002, donde aumentó en un 1,06\% y aunque en los períodos 2002-2003 y 2003-2004, disminuyó, solo fue en un $0.38 \%$ y en un $1 \%$ respectivamente.

Cuando se realizó el análisis de los procesos contractuales contra Emcali, se encontró en lo relacionado con los de la clase laboral y contencioso que éstos eran los que mayores demandas habían recibido en el período 20022003.

El aumento en costos para la empresa del año 2002 al 2003 por concepto de demandas en las clases laboral y contencioso sería de \$58942,1 en caso de ser fallados en contra, le significaron unos costos a Emcali de 961,5 millones de pesos.

De acuerdo a los indicadores de gestión financiera de Emcali, en cuanto a contratación, se puede decir que éstos han incidido negativamente en su estructura de costos, derivados del mal diseño económico e inadecuada selección del contratista, lo cual se evidencia en el alto porcentaje de variación del 90\% que tuvieron los gastos en sentencias y conciliaciones surgidas por el incumplimiento de los objetivos trazados y estándares requeridos por la empresa.

De acuerdo a lo anterior, se puede decir que no ha habido una flexibiliza- ción de la organización de la empresa, la cual no ha dado una eficaz respuesta a los retos planteados por el modelo de la Ley 142, en cuanto al fomento de la eficiencia empresarial y de la idoneidad para beneficiar a los usuarios.

Al preguntarles a los entrevistados acerca de la cantidad de contratos en los que se no se cumple con las garantías contractuales, se obtuvo que aunque la mitad respondieron que de los contratos a su cargo en ninguno se faltó a las garantías contractuales, el $41,66 \%$ respondió que esto se da en una cantidad baja y el $8,33 \%$ que se da en una cantidad media, lo cual implica que en la etapa post-contractual, ha habido riesgos en el diseño de algunos contratos.

Por otro lado, cuando se les preguntó acerca del porcentaje de los contratos en los que suele solicitarse aplazamiento, ha de destacarse que el $33,33 \%$ respondió que entre el 15\% y el $40 \%$ de los contratos y aunque el $50 \%$ dijo que se da sólo entre el $0 \%$ y el $15 \%$, se puede decir que en ésta etapa hay riesgos de que se presenten conductas oportunistas, ante una posible renegociación, derivada de la prórroga en algunos de los contratos.

En cuanto a las sanciones económicas, el $83,33 \%$ de los interventores respondieron que entre el $0 \%$ y el $15 \%$ de los contratos se han presentado multas, lo cual implica también que en la etapa post-contractual han habido casos de contratos en los que no se ha cumplido con las condiciones establecidas, lo cual como ya se había mencionado antes, se da principalmente 
por parte del contratista.

En el caso de los contratos en los que ha habido que adicionar, el 41,66\% respondió que entre el $15 \%$ y el $40 \%$ hubo que adicionar, lo cual implica que en la etapa pre-contractual de algunos contratos, no se tienen en cuenta las posibles eventualidades que se pueden presentar en el transcurso del tiempo establecido para el cumplimiento del objeto.

"Estudios de los últimos años indican que en Colombia el monto del soborno en aquellos contratos que han sido objeto de prácticas corruptas sería de entre un 10\% y un $25 \%$ del valor de los contratos, para un promedio aritmético de 19\%. Ese nivel de soborno haría que los sobrecostos directos para el país productor de las prácticas corruptas en materia de contratación pública, podría llegar a niveles del $10 \%$ del total de compras estatales. La encuesta hecha por el Centro Nacional de Consultoría en febrero de 2002 a funcionarios públicos y empresarios muestra cifras impactantes en cuanto a la incidencia de corrupción en el campo de las compras estatales. Los funcionarios públicos entrevistados declaran que en el $49.7 \%$ de las licitaciones públicas en Colombia se realizan bajo pagos adicionales para asegurar la adjudicación de contratos. La percepción de los funcionarios es corroborada, asimismo, por los empresarios que en un $62 \%$ coincidieron en que "siempre o casi siempre" las empresas recurren a pagos extraoficiales para ganar concursos o licitaciones públicas, dándose una abierta complicidad por parte de los empresarios de conductas ilegales en sus relaciones con el Estado" (Arteaga e Isaza, 2005, pág 11).

"Dentro de las conclusiones derivadas de la encuesta se afirma que el alto nivel de corrupción en la contratación pública parece haber distorsionado seriamente los elementos de competencia sana y abierta que constituyen la esencia del proceso licitatorio. La existencia de monopolios de contratistas es reconocida como la irregularidad más frecuente en los procesos de licitación y es ratificada por el $73 \%$ de empresarios con mayor dependencia de la contratación pública" (Badel, 1999).

Los costos de transacción aumentan ante la presencia de factores como: La ineficiencia que da lugar a una disminución en la calidad del servicio prestado, la cual surge ante la debilidad de los sistemas de planeación y control, la inestabilidad de los funcionarios y la falta de incentivos para las gestiones eficientes; otro factor es la discrecionalidad de los funcionarios, es decir, éstos sólo se limitan a hacer lo que les ordena la Ley, lo cual les sirve de evasiva para no tomar decisiones conducentes a la solución de los problemas que se presenten; por otro lado está el monopolio de los servicios, el cual hace que no se tengan incentivos para mejorar los bienes $\mathrm{y}$ servicios ofrecidos, dada la ausencia de competidores; otro caso es el de la baja probabilidad de ser descubiertos, la cual influye en la mala calidad del control y por lo tanto da lugar a un mayor incentivo para adoptar una conducta oportunista.

\section{Conclusiones}

- Dado que el 65,65\% de los contratos son incompletos según el mo- 
delo de Regresión logística, se puede decir que una de las causas de ineficiencia de Emcali, radica en que los contratos celebrados entre la empresa y los proveedores, están económicamente mal diseñados, lo cual da pie a que se presenten conductas oportunistas, tanto en la etapa pre-contractual, en la cual, dada la discrecionalidad de los funcionarios, éstos podrían manipular los requisitos y ajustar las recomendaciones, de acuerdo a su conveniencia; en la etapa contractual, donde el hecho de que no se hagan las revisiones periódicas, da lugar a que el objeto contratado no se haga de manera oportuna, ni con las calidades requeridas, lo cual va en contra de la eficiencia de la empresa, en cuanto a costos y en cuanto a la calidad el servicio suministrado y finalmente en la etapa post-contractual, donde pueda que no se cumpla con las garantías establecidas, dando lugar a un conflicto entre la partes.

- En este documento se identifica que uno de los principales problemas del mal diseño de los contratos es la violación de la Ley 142 y en consecuencia de la Resolución No. 000069 , pues aquí se encuentra la principal causa de costos de transacción. Las infracciones contra el régimen de contratación, se traducen en las transgresiones más frecuentes contra el funcionamiento de los contratos como: Inadecuado uso de la "urgencia manifiesta"; asesorías profesionales y contratos con fiducias que dan pie a diversas interpretaciones de la ley. No hay planeación en la contratación pú- blica, los controles son insuficientes y no hay control en las entidades sobre los procesos de ejecución de los contratos, lo cual impide que se cumplan las condiciones de calidad; además por otro lado, los costos de transacción son muy altos, especialmente en lo referente al cumplimiento de los contratos, pues el sistema legal que los debería garantizar, tiene dificultades en la aplicación de las leyes.

- De nada sirve tener excelentes estatutos de contratación, desde el punto de vista de la efectividad y los principios que rigen la administración pública, si quienes elaboran los procesos poseen racionalidad limitada, hecho que no les permite ajustarse a dichos estatutos; esto genera el espacio a una conducta oportunista que en ocasiones, alguna de las partes del contrato tiene su propia interpretación de la norma, y pueden intentar sacar el máximo beneficio individual a cualquier circunstancia y donde las insuficiencias materiales actúan con mayor fuerza que los códigos de ética o los sistemas de valores.

- De este texto se puede tener la siguiente reflexión: Cuando no existen instituciones que garanticen un intercambio eficiente, surgen incentivos para que los agentes busquen un beneficio privado, sin importar el costo social que esto implique. Para que el intercambio marche como debe ser, es necesario detallar claramente los derechos de propiedad, pues de lo contrario el intercambio se hará a costos de transacción altos y no habrá incentivos para lograr una asignación eficiente de los recur- 
sos, por tanto, si no hay incentivos para cumplir las leyes, dado que es costoso cumplirlas, los agentes decidirán incumplir, y esto afectará el desarrollo económico, puesto que será más eficiente buscar transferencia de rentas, que la creación de riqueza.

\section{Bibliografía}

ARTEAGA C., Ana María y Omar Isaza G, (2005). Una aproximación a las estrategias de los corruptos. Instituto popular de capacitación -IPCColombia.

BADEL R., Martha Elena, (1999). Costos de la corrupción en Colombia. "Serie: Archivos de Macroeconomía". Documento No. 205. Departamento nacional de planeación- Unidad de análisis macroeconómico. Bogotá.

BIERMAN, Jr, Harold y otros, (1994). Análisis cuantitativo para la toma de decisiones. Madrid. Addison Wesley Iberoamericana.

COASE, Ronald H, (1960). "El problema del costos social"

COASE, Ronald H, (1998). "The Nature of Firm", Económica, No.4:386-405. Nov 1937. Versión española: "La naturaleza de la empresa" en: Lecturas de microeconomía y economía industrial. Compiladores y traductores: Quintillan Ahijado, Manuel y Cornejo Fernández, José Andrés. Tercera Parte: Teoría de la empresa, Págs. 235-256. Ediciones Pirámide. UNED- CECA. Colección Economía y Empresa, sección Lecturas de Economía. Madrid - España.

CROCKER, Keith y Reynolds Kenneth, (1993). The efficiency of incomplete contracts: an empirical analy- sis of the air force procurement, "Rand Journal of Economics" vol 24(1) Spring.

EMCALI, Acueducto y Alcantarillado, Reseña histórica. Disponible en Web: http://www.Emcali.com.co/acueducto/ historia.html

EMCALI, Energía, Reseña histórica. Disponible en Web: < http:// www.Emcali.com.co/ energia/ historia.html >

EMCALI, (2.003). Informe de gestión EMCALI resumen ejecutivo Año 2.002. Gerencia de planeación.

EMCALI, (2.004). Informe de Gestión EMCALI Enero-Diciembre de 2.003. Gerencia de planeación.

EMCALI, (2.005). Informe de gestión EMCALI Enero-Diciembre de 2.004. Gerencia de planeación.

EMCALI, Nuestra empresa, Reseña histórica. Disponible en Web: $<$ http://www.Emcali.com.co/corporativa/historia.html

EMCALI, Telecomunicaciones, Reseña histórica. Disponible en Web:

$<$ http//www.Emcali.com.co/telecomunicaciones/historia.html >

GORBANEFF, Yuri, (2002). Contratación pública en Colombia y la teoría económica. "Serie: Archivos de Economía". Documento No. 205. Departamento nacional de Planeación-Dirección de estudios económicos. Bogotá.

LEY 80 (1994, 28 de Octubre) "Por la cual se expide el statuto General de contratación de la administración pública." Decretada por el Congreso de Colombia.

LEY 142 (1.994, 11 de Julio) "Por la cual se establece el régimen de los servicios públicos domiciliarios y se dictan otras disposiciones." Decretada por el Congreso de Colombia.

MARCH G., James y Herbert A. Simon, (1961). Teoría de la organización. Bar- 
celona. Editorial Ariel. Versión en español 1980

MILGROM, Paul y Roberts John, (1994). Economía organización y gestión de la empresa. España. Editorial Ariel S.A.

NORTH, Douglass C., (1998). La teoría económica neo-institucionalista y el desarrollo latinoamericano. Proyecto PNUD "Red para la gobernabilidad y el desarrollo en América Latina”. Realizado por: Instituto internacional de gobernabilidad. Barcelona

NORTH, Douglas C., (1990). Instituciones, cambio institucional y desempeño Económico. México. Fondo de cultura económica.

RESOLUCIÓN No. $001800(2.000,20$ de Septiembre) "Por la cual se expiden normas de contratación para EMCALIE.I.C.E. E.S.P."

RESOLUCIÓN No. 000069 (2.003, 31 de Enero) "Por medio de la cual se expiden normas de contratación para EMCALIE.I.C.E. E.S.P."

RESOLUCIÓN No. 000820 (2.004, 20 de Mayo) "Por la cual se expide el estatuto interno, se establece la estructura organizacional de las empresas municipales de Cali EMCALI E.I.C.E. E.S.P., se adopta la planta de cargos, se determinan las competencias generales por áreas y se adoptan otras determinaciones."

SABATÉ, Jordi M., (2001). Gestión privada de servicios públicos: La externalización outsourcing) en la administración pública. V Congreso del CLAD2-35.

SAUSSIER, Staphane, (2000). Transaction cost and contractual incompleteness: the case of Electricite de Fran$c e$, "Journal of Economic Behavior and Organization” vol. 42, pp. 189-206.
SCHOTTER, R. Andew., (1.998). Microeconomía. Un enfoque moderno. México. Compañía editorial Continental, S.A.

SIMON, Herbert A . El comportamiento administrativo. Editorial Aguilar. España.

SIMON, Herbert A. Organizaciones $y$ mercados, (1991). http:// www.eumed.net/cursecon / $0 /$ recomiendo.phtml. Tomado de Journal of Economic Perspectives, Volumen 5 Número 2, Primavera, Página 25-44. Traduccion de Guillermo Ramírez Hernández.

SIMON, Herbert a., James G. March, (1980). Teoría de la organización. Editorial Ariel.España.

VARELA Barrios, Edgar, (2002). “Cómo evitar el colapso de EMCALI- los retos de la provisión adecuada de los servicios públicos domiciliarios en Colombia", Cali: PLIEGOS ADMINISTRATIVOS Y FINANCIEROS, Facultad de Ciencias de la Administración, Universidad del Valle, No. 39.

WILLIAMSON, Oliver E., (1988) “Corporate Finance and Corporate Governance". The Journal of Finance, Vol. 43, No. 3 pp 567-591.

WILLIAMSON, Oliver E., (1989). Las instituciones económicas del capitalismo. México. Fondo de cultura económica.

WILLIANSOM, Oliver E. y Winter, Sydney G. (Compiladores), (1991). La naturaleza de la empresa, Orígenes, evolución y desarrollo. Fondo de cultura económica. Versión en español.1996.

WILLIAMSON, Oliver E., (1991). Mercados y jerarquías: su análisis y sus implicaciones antitrust. México. Fondo de cultura económica. 